\title{
Journal of Linguistics
}

http://journals.cambridge.org/LIN

Additional services for Journal of Linguistics:

Journal of Linguistics

Email alerts: $\underline{\text { Click here }}$

Subscriptions: $\underline{\text { Click here }}$

Commercial reprints: $\underline{\text { Click here }}$

Terms of use : $\underline{\text { Click here }}$

\section{Polydefinites in Greek: Ellipsis, close apposition and expletive determiners}

MARIKA LEKAKOU and KRISZTA SZENDRÖI

Journal of Linguistics / Volume 48 / Issue 01 / March 2012, pp 107 - 149

DOI: 10.1017/S0022226711000326, Published online: 19 December 2011

Link to this article: http://journals.cambridge.org/abstract_S0022226711000326

How to cite this article:

MARIKA LEKAKOU and KRISZTA SZENDRÖI (2012). Polydefinites in Greek:

Ellipsis, close apposition and expletive determiners. Journal of Linguistics, 48, pp 107-149 doi:10.1017/S0022226711000326

Request Permissions : $\underline{\text { Click here }}$ 


\title{
Polydefinites in Greek: Ellipsis, close apposition and expletive determiners ${ }^{1}$
}

\author{
MARIKA LEKAKOU \\ Goethe University of Frankfurt \\ KRISZTA SZENDRŐI \\ University College London
}

(Received 27 May 2008; revised 7 April 20II)

Greek polydefinites are cases of adjectival modification where the adjective features its own definite determiner. We propose an account of the phenomenon that treats it as an instance of close apposition. Like close appositives, polydefinites in Greek instantiate multiple definite determiners, display a freedom in word order, and involve a restrictive interpretation. We propose that close apposition in Greek forms a complex DP out of two DPs which are in a sisterhood relationship through identification of the Referential roles within the DPs. This operation, semantically tantamount to set intersection, is constrained to apply only when the resulting set is not co-extensive with either initial set. This ensures the restrictive interpretation of one DP over the other. The fact that in polydefinites, it is always the DP containing the adjective that obligatorily satisfies the constraint has to do with the presence of noun ellipsis within that DP: (noun) ellipsis is known to come with a disanaphora requirement. We show that noun ellipsis is also responsible for the distribution of adjectives and adjective interpretations, as well as those discourse effects of polydefinites that have been thought of as the result of a DP-internal Focus projection. Finally, we make a proposal for the encoding of definiteness in Greek, consonant both with the existence of polydefinites in the language and with the prerequisite for set intersection among DPs: the overtly realized Greek definite determiner does not itself contribute an iota operator but preserves the $<\mathrm{e}, \mathrm{t}\rangle$ denotation at the DP level. Our proposal thus deals not only with the multiple occurrence of definite determiners in a construction that picks out a single discourse referent, but also with the compositionality problem that such a situation

[I] We are grateful to the audiences of the MIT Workshop on Greek Syntax and Semantics, the workshop Atoms and Laws of the Noun Phrase, the 4oth Meeting of the North East Linguistics Society, and the participants of the Egg school 2010 in Constanta. We are particularly indebted to Artemis Alexiadou, Hector Campos, Marcel den Dikken, Sabine Iatridou, Alexia Ioannidou, Olaf Koeneman, Luisa Marti, Ad Neeleman, Øystein Nilsen, Melita Stavrou, Jeroen van Craenenbroeck, Hans van de Koot, Reiko Vermeulen, Edwin Williams and Hedde Zeijlstra. The paper has also benefited from the scrutiny of three anonymous $J L$ referees. All errors remain our own. The first author would like to acknowledge that a major part of this work was carried out with the financial support of the European Science Foundation (EURYI grant for the project European Dialect Syntax to Sjef Barbiers). 
gives rise to. In the final part we tie the cross-linguistic (un)availability of expletive determiners of the Greek type to the (un)availability of morphologically realized case.

\section{INTRODUCTION}

In this paper we propose an account of the so-called polydefinite construction in Modern Greek (henceforth Greek), exemplified in (I), which capitalizes on the similarities of the construction to close appositives, as in (2): ${ }^{2}$

(I)
(a) $\mathrm{i}$
asimenia $\mathrm{i}$
pena
(b) $\mathrm{i}$

the.NOM silver the.NOM pen
$\mathrm{i}$ pena $\mathrm{i}$ asimenia
the.NOM pen the.NOM silver
'the silver pen'
(2) (a) $\mathrm{O}$ aetos to puli
the.MASC eagle the.NEUT bird
(b) to puli $\mathrm{O}$ aetos
the.NEUT bird the.MASC eagle
'the eagle that is a bird'

Polydefinites, also known under the rubric of determiner spreading, are instances of an adjective modifying a noun where the noun and the adjective are each accompanied by their own determiner (the terms 'polydefinite' and 'monadic definite' are due to Kolliakou 2004). ${ }^{3}$ In addition to polydefinites, Greek has at its disposal 'regular' adjectival modification, the so-called monadic definite. However, as already noted by Alexiadou \& Wilder (I998), Alexiadou (200I), Campos \& Stavrou (2004) and Kolliakou (2004), there are several differences between the two. First, although in polydefinites the adjective is freely placed either pre- or post-nominally, as shown in (I), monadic definites only allow the adjective in prenominal position, witness (3):

(3) (a) i asimenia pena

the silver pen

(b) $*_{\mathrm{i}}$ pena asimenia
the pen silver

[2] The close appositive in (2) (from Stavrou 1995) features two nouns that differ in gender. This is a close appositive in Greek, by virtue of the fact that in this language aetos 'eagle' happens to be homophonous to aetos 'kite'. We return to the gender facts in the following section. Whenever relevant, we only indicate gender specification on the determiner, although gender is also encoded on the noun (and on any attributive adjective). Likewise, although there is case agreement within the Greek DP, we only indicate it on the determiner. See footnote 5 below on 'case spreading'.

[3] As we will discuss in Section 2.2, the term 'polydefinite' is a misnomer, as the meaning of these NPs is, in terms of definiteness, no different from that of a monadic definite. However, for want of a better alternative, we continue to use this term. 
Secondly, adjectives in the polydefinite construction are obligatorily interpreted restrictively. ${ }^{4}$ In (4) below, from Kolliakou (2004), determiner spreading is disallowed, because it is impossible to interpret the adjective dilitiriodis 'poisonous' restrictively with respect to the noun kobres 'cobras', since all cobras are poisonous (there are no non-poisonous cobras). In line with common practice, we use the '\#' symbol to notate this kind of interpretative ill-formedness.

(4) Idame tis dilitiriodis (\#tis) kobres.

saw.IPL the poisonous the cobras

'We saw the poisonous cobras.'

Thirdly, there is no variant of the polydefinite construction with the indefinite determiner (Alexiadou \& Wilder I998; but see Stavrou 2009):

(5) (a) *mia pena mia asimenia

a pen a silver
(b) *mia asimenia mia pena

a silver a pen

Finally, and quite obviously, as the terms 'determiner spreading' and 'polydefinites' suggest, a crucial property of the construction is the occurrence of

[4] Although the restrictive interpretation is clearly the dominant one, there are cases where a non-restrictive interpretation is available as well. For instance, the example in (i) below does not require that the speaker have more than one brother. Note, though, that in that case it involves a special interpretation of the adjective (i.e. it cannot simply mean that the speaker's (unique) brother is clever).

(i) o eksipnos o adelfos mu

the clever the brother me.GEN

'my brother the wise-ass'

Panagiotidis \& Marinis (20II), citing Manolessou (2000), mention more cases, for instance (ii), naming a famous building in Thessaloniki. In fact, proper names in general can take two definite articles. We believe that names may not be strictly speaking restrictive, but it seems reasonable to assume that such usage is a 'frozen' reflection of a former restrictive use.

(ii) o Lefkos o Pirgos

the white the tower

'the White Tower'

Finally, cases such as (iiia) seem to be appropriate in situations where the referent of the DP is directly accessible in the discourse (i.e. topical). It remains to be seen how widespread such usage is and what the exact pragmatic status of such cases is. We leave this issue unresolved here.

(iii) (a) Vjike ekso ston krio ton kero. went.3SG out in.the cold the weather

'S/he went out in the cold weather.'

(b) Bike sto kenurjo tis to aftokinito ke efije.

entered.3SG in.the new hers the car and left.3SG

'S/he got into her/his new car and left.' 
multiple determiners. As we will see in Section 4.2.2, deriving this property is a far from trivial task.

Turning now to close appositives in Greek, what we have is two nouns each of which features its own determiner, as (2) above illustrates. We observe that close appositives display the same properties identified above for polydefinites. ${ }^{5}$ First, as shown in (2) above and repeated here in (6), the order within the larger constituent is free:

(6) (a) o aetos to puli the eagle the bird

(b) to puli o aetos the bird the eagle 'the eagle that is a bird'

Secondly, one of the subparts of close appositives is obligatorily interpreted restrictively with respect to the other subpart. See (7), from Stavrou (I995: I23) (see also Kolliakou 2004):

(7) De su ipa oti sinandisa ton Antoniou NEG you.GEN said.ISG that met.ISG the Antoniou to filologo, ala ton Antoniou to mathimatiko. the philologist but the Antoniou the mathematician 'I didn't tell you I met Antoniou the philologist, but Antoniou the mathematician.'

Thirdly, as pointed out by Stavrou (I995), close apposition too necessarily involves definite DPs:

(8) (a) *enas aetos (ena) puli an eagle a bird

(b) *ena puli (enas) aetos a bird an eagle

And finally, similarly to polydefinites, close appositives too feature multiple determiners.

Our proposal is to derive the core properties that close appositives and polydefinites share from a common structure and a common semantic process, that of identification of Referential roles. This, we will argue, is at the heart of close apposition as a superordinate category comprising close appositives and polydefinites. Concretely, both close appositives and polydefinites are DPs that consist of DP subparts. The only difference is that in polydefinites

[5] As an anonymous $J L$ referee points out, in traditional grammars of Greek, both close appositives and polydefinites are discussed under the rubric of 'same-case' modifiers. In a typical monadic DP in Greek, case is shared by all the elements within the DP. The fact that this seems to carry over to polydefinites and close appositives is consistent with our claim that such complex DPs form a single argument DP. We briefly return to this point in Section 4.2.2. In Section 5 we discuss the relevance of the availability of morphological case in a given language for the existence of polydefinites. 
one DP subpart contains noun ellipsis. A number of properties exclusive to polydefinites are related to this.

In Section 2 we present our proposal for the process of identification of Referential roles (R-roles). In Section 2.I we discuss the syntax and semantics of this process. Section 2.2 addresses the view of the encoding of definiteness that the nature of close apposition in Greek forces upon us. What enables identification of R-roles at the level of DPs in Greek is the expletive nature of its determiners, which is responsible for the predicative nature of Greek DPs. In Section 2.3 we discuss two apparent problems for the view of the Greek determiner proposed. In Section 3 we show that the core properties displayed by Greek close apposition follow from the operation of R-role identification, in combination with a restriction on its application. In Section 4 we turn to polydefinites and in particular to the effects of the noun ellipsis contained in a polydefinite DP. We also compare our analysis to existing alternatives with respect to the multiple occurrence of determiners and the discourse properties of the construction. In Section 5 we provide a cross-linguistic perspective on the (un)availability of Greek-style close apposition and the significance of case in addition to expletive determiners. Section 6 summarizes.

\section{GREEK CLOSE APPOSITION AS R-ROLE IDENTIFICATION}

\section{I Syntax and semantics of R-role identification}

Recall example (7), repeated here as (9): ${ }^{6}$

(9) De su ipa oti sinandisa ton Antoniou NEG you.GEN said.ISG that met.ISG the Antoniou to filologo, ala ton Antoniou to mathimatiko. the philologist but the Antoniou the mathematician 'I didn't tell you I met Antoniou the philologist, but Antoniou the mathematician.'

[6] The parallel we draw is between polydefinites and close, not loose appositives (see also Stavrou 1995: 218, Kolliakou 2004: 274, Panagiotidis \& Marinis 20II). That polydefinites are dissimilar from loose appositives is shown in Alexiadou \& Wilder (1998); however, these authors do not distinguish between close and loose appositives. In Lekakou \& Szendröi (2007) we discuss the distinction in detail and briefly summarize here. Close appositives occur within a single prosodic unit, whereas loose appositives involve an intonational break between the two subparts. Loose appositives occur with any grammatical category, whereas close appositives are only possible with nominals (Payne \& Huddleston 2002: 447ff.; Huddleston, Payne \& Peterson 2002: I350ff.). Finally, in loose apposition the first subpart (anchor in the terminology of many authors) is referential, and the second (often called appositive) is predicative. For the latter, semantic property, see especially Potts (2005) and Doron (1992, I994). Given our proposal, neither subpart of a close appositive is referential to the exclusion of the other (in fact, as we argue in Section 2, semantically speaking, both DPs partaking in close apposition are of the predicate type, i.e. $<\mathrm{e}, \mathrm{t}>$ ). Loose apposition has been taken by several authors to involve a parenthetical structure (see among others Dehé \& Kavalova 2007 and references therein, Ackema \& Neeleman 2004, and also Potts 2005). 
In (9) neither 'Antoniou' nor to filologo 'the philologist'/to mathimatiko 'the mathematician' suffices to unambiguously determine the intended referent, although these expressions are independently perfectly well-formed and capable of picking out a referent. What happens in (9) is that referents are picked out through 'collaboration' of the relevant expressions. In close apposition, in other words, both subparts jointly contribute to reference. This basic property of close apposition, we propose, comes about as a result of identification of R-roles within the larger constituent. ${ }^{7}$

In the work of Williams (I98I, I989), Higginbotham (I985), Zwarts (I993) and Baker (2005), nominals come with an R-role, in addition to any other thematic roles they may have. The R-role is in fact their external theta role, and it is what enables a nominal element to act as a referential argument. In Williams' system, for instance, when a nominal occupies an argument position, its R-role is bound by a thematic role of the selecting predicate, whereas when the nominal occurs as a predicate, it assigns the R-role to its subject.

Our proposal is that in close apposition the R-role contributed by one nominal expression is identified with the R-role contributed by another, as schematically presented in (Io):

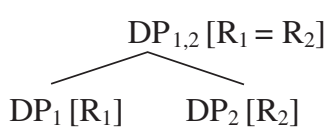

Identification of thematic roles within nominal categories is not new. Higginbotham (1985) proposed that adjectival modification involves

[7] The proposal that follows has been developed with Greek close apposition in mind. Although we believe that the essence of the proposal will be relevant for other languages, we do not know enough about the syntax of close appositives in other languages to make a claim. At least in English it seems clear that R-role identification cannot take place among any two DPs: English close apposition, as in (i), generally requires a proper name, whereas Greek can have two common nouns: compare example (2)/(6) above with (ii) below:

(i) Burns the poet

(ii) *the cannon the weapon $/ *$ the weapon the cannon

In our terms, the contrast between Greek (2) and English (ii) is related to the different properties that Ds have in the two languages, as will become clear in the course of this paper. As for (i), we do not consider it equivalent to the poet Burns (for which see AcunaFariña 2009), so that another difference emerges, having to do with ordering freedom. 
identification of a theta role of the adjective with the R-role of the noun, as illustrated in (II):

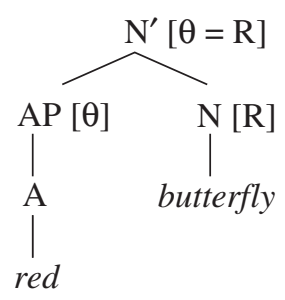

Higginbotham's identification is semantically tantamount to set intersection (see also Heim \& Kratzer's (I998: 65) predicate modification rule): the set denoted by the adjective is intersected with the set denoted by the noun, such that a red butterfly refers to something that is both red and a butterfly. Our proposed R-role identification is also interpretatively set intersection: $o$ aetos to puli 'the eagle that is a bird' refers to something that is both a bird and an eagle (as opposed to o aetos to simvolo 'the eagle that is a symbol'). For intersection among DPs to be possible, we need to assume that the definite determiner in Greek does not saturate the NP predicate. In other words, the Greek DP does not denote in type $e$, but rather in type $<e, t>$, the predicate type typically associated with NP denotations. The $e$-type denotation is derived at the topmost DP level, and not within each DP subpart of close apposition. In Section 2.2 we return to this and propose that the locus of (semantic) definiteness usually associated with D heads is actually a separate functional head in Greek, located above and thus scoping over DP.

A noteworthy difference between the structures in (IO) and (II) is that only in the latter is there an asymmetric relation between modifier and modifiee. Our proposal is that, when theta role identification operates on two R-roles (as opposed to an R-role and a different theta role), it takes place under sisterhood, i.e. within a multi-headed syntactic structure. For a discussion of the conceptual issues that arise in admitting such structures in our grammar, see Baker \& Stewart (1999). (These authors implement an account of serial verb constructions involving multi-headed structures.) See also Williams (1994: II) and Hiraiwa \& Bodomo (2008). For one thing, as long as the categorial specification of the subparts is the same, it is unclear on what conceptual grounds we can solidly exclude a structure such as (Io). After all, adjunction of one DP to another would look much like (Io), the difference being that one DP should still be, somehow, distinguishable as the head. The claim that in close apposition neither nominal counts as the head is supported by empirical evidence based on agreement facts. As discussed in Lekakou \& Szendröi (2009), when the close appositive involves two head nouns whose 
gender specification is distinct, gender agreement with a predicative adjective is evidently possible with either subpart, as illustrated in (I2a) and (I2b). This variation is compatible with the idea that neither subpart of a close apposition is the unique head of the construction. Compare (I2C), which is similar to close appositives in that a pronoun and a full nominal DP are syntactically combined. However, here, arguably the pronominal part is the unique head. (For example, there is no ordering freedom in this case.) As expected, this construction only allows verbal agreement with one part, namely the pronominal one:

(I2) (a) $\mathrm{O}$ aetos to puli ine megaloprepos/megaloprepo. the.M eagle.m the.N bird.N is majestic.M/majestic.N

(b) To puli o aetos ine megaloprepos/megaloprepo. the.N bird.N the.m eagle.M is majestic.M/majestic.N 'The eagle that is a bird is majestic.'

(c) Emis i glosoloji piname/*pinane. we.NOM the linguists.NOM are.hungry.IPL/are.hungry.3PL 'We linguists are starving/hungry.'

R-role identification solves a potential theta-theoretic problem: how can two DPs occur in the context of a single predicate without incurring a violation of the Theta Criterion? Put differently, why do close appositives/ polydefinites not require as many theta-role assigners as the number of DPs they consist of? Assuming that the R-role is the thematic role implicated in theta-role assignment (as in Williams 198I), then it is precisely through identification of the R-roles that the potential violation of the theta criterion does not occur. A similar question arises in cases of complex predicate formation as conceived in Neeleman \& van de Koot (2002). The answer to it also implicates identification among theta roles. Consider, for instance, an example from Dutch in (I3):

$$
\begin{aligned}
& \ldots \text { dat } \mathrm{Jan}_{\mathrm{i}} \text { Marie }_{\mathrm{j}} \text { naakt } \\
& \text { that } \mathrm{Jan} \text { ontmoette. } \\
& \text { 'that Jan met Marie naked.' met }
\end{aligned}
$$

One may reasonably ask how it is possible that two predicates (ontmoette 'met' and naakt 'naked') can both discharge their theta roles in the presence of only one DP. If the theta role of the adjectival predicate becomes identified with either the internal or the external theta role of the verbal predicate, the identified theta role can be discharged in the presence of a single DP. A similar reasoning applies to close apposition: even though both $\mathrm{DP}_{1}$ and $\mathrm{DP}_{2}$ are potential arguments by virtue of their own R-roles, by identification of these R-roles it is the highest DP alone that acts as a single argument. In this sense, we can think of close apposition as the nominal 
counterpart of complex predicate formation, i.e. as complex ARGUMENT formation.

It now follows that only nominal phrases can partake in close apposition, since close apposition is defined as involving identification of R-roles and since only nominal elements have an R-role at their disposal. This is a welcome result, since indeed only nominal constituents can be brought together under close apposition, in contrast to loose apposition (as mentioned in fn. 6 above).

Before we show how this proposal for close apposition applies to close appositives and polydefinites, we need to return to the issue of where definiteness is encoded in a language like Greek, if close apposition involves DPs of $<\mathrm{e}, \mathrm{t}>$ type.

\subsection{The locus of definiteness}

In the previous section, R-role identification was defined semantically as set intersection. This is ultimately forced upon us by the facts of life in a language like Greek: a polydefinite such as to megalo to spiti 'the big house' refers to something that is both big and a house. Thus, nominal elements that are formally DPs in Greek have to be granted an $<\mathrm{e}, \mathrm{t}>$ denotation, otherwise set intersection, which constitutes part of the interpretation of polydefinites, will be impossible. In fact it can be shown that the determiners in the polydefinite (or in a close appositive, for that matter) are not interpreted in the usual way; this in turn means that DPs in Greek are not of the usual (namely $e$ ) type. The polydefinite to megalo to spiti is felicitously used in a context where there cannot, in fact, be a unique house, as that would mean that the adjective would not be able to be interpreted restrictively: if there is only one house, and that house is big, there cannot be another, non-big house. But, as we saw in the introduction, in polydefinites the adjective is necessarily interpreted restrictively. So the determiner on the noun is not semantically real. But neither is the one on the 'adjectival' DP: in uttering to megalo to spiti the speaker makes no commitment whatsoever that there is a unique big entity. Thus, it seems that, semantically, both definite determiners are vacuous at the position where they surface. That is not to say, however, that there is no definiteness in the polydefinite: what is unique is the element in the intersection of the two DP categories. In other words, definiteness is interpreted on, or actually above, the larger DP.

To account for the existence in Greek of structures involving multiple D heads but only one semantically definite creature, we would like to propose that all instances of the Greek definite determiner are semantically expletive. What looks like the source of definiteness, in structures with one (e.g. monadic definites) or multiple determiners (i.e. close apposition), is semantically empty, and what makes the semantic contribution is a 
phonologically null element. The definite determiner is one and the same entity in all its guises: a semantically inert element., ${ }^{8,9}$

In particular, we would like to propose that two separate functional heads are projected in Greek instead of one D head. The higher head, which we call Def (for Definiteness), is the one associated with the usual semantics, i.e. contributes an iota operator and a uniqueness presupposition. This head is phonologically null. The lower one is semantically inert and is spelled out by the definite determiner. Syntactically, Kase selects Def, which selects D, which in turn selects NP (or NumP; we do not discuss the lower structural make-up of the nominal projection here). We discuss the importance of KaseP in Section $5 \cdot{ }^{10}$

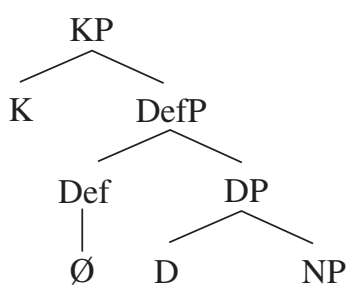

Semantically, the nominal at the DP level is still type $<\mathrm{e}, \mathrm{t}>$. It is only at the DefP level that we obtain a referential nominal of type $e$. In the case of polydefinites the proposed syntactic symmetric structure gives rise to the intersection of two DP predicates of type $<\mathrm{e}, \mathrm{t}>$. This is precisely the required interpretation, as we discussed in Section 2.I above. ${ }^{11}$

[8] A similar line of reasoning has been suggested for negative concord by Zeijlstra (2004) in particular for languages like Greek, namely Strict Negative Concord languages. Zeijlstra argues that in such languages the marker of sentential negation is actually not semantically negative. Rather, semantic negation is contributed by a covert negative operator, and the overtly realized 'negative' elements (negative markers and negative polarity items) are semantically non-negative.

[9] There is an alternative approach, which has been assumed by essentially every existing proposal in the literature on polydefinites, according to which one, and only one, of the multiple determiners makes the relevant semantic contribution. As we discuss extensively in Section 4.2.2, we think such an approach is problematic.

[Io] For different executions of the idea of splitting the DP in two functional layers (based more on syntactic and less on semantic facts), one hosting the overt definite article and the other encoding semantic definiteness, see Karanassios 1992, Androutsopoulou 1995, Stavrou I996, and Tsimpli \& Stavrakaki 1999.

[II] In the tree diagrams above, two DPs are merged, but only one empty operator is projected above the composite DP, giving rise to a unique saturated nominal. We can exclude the possibility of merging multiple nominal projections that have a $\mathrm{D}$ and a covert operator each, because there would be no semantic composition rule to combine two saturated nominals (other than coordination, of course); but see Velegrakis (20II) for a proposal. 
(I5) (a)

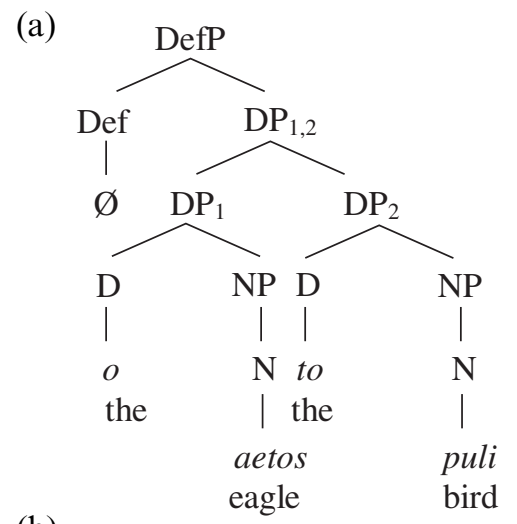

(b)

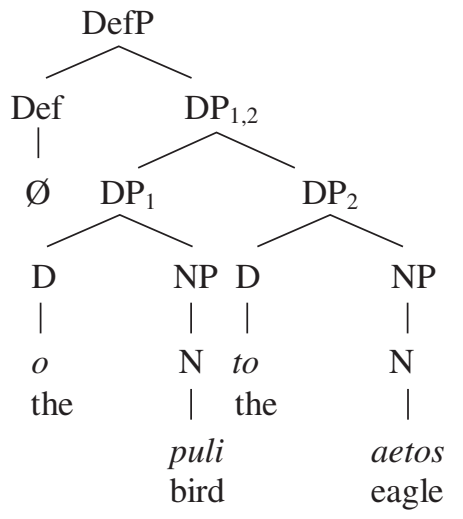

The proposal that definiteness in Greek is split into a phonologically empty but semantically active part (Def) and a phonologically overt and syntactically active, but semantically inert part (D) is compatible with the syntactic and semantic properties of close apposition, and crucially applies, not just to polydefinite DPs and close apposition more in general, but to monadic DPs just as well. As we will see especially in Section 4, this level of generality constitutes a non-trivial advantage of our analysis, compared to existing alternatives.

At this point, the question arises if there is robust independent evidence in the language for such a split Def-D structure. We believe that the obligatory presence of articles on proper names in the language may provide the required positive evidence. In Greek, proper names require the definite determiner, as (I6) shows. (See the next section for some discussion of proper names in non-argument contexts.)

(I6) *(O) Janis eftase stin ora tu. the John arrived on.the time his

'Janis arrived on time.'

We follow the philosophical tradition that takes proper names to be rigid designators (Kripke 1980, contra most recently Elbourne 2005 and 
Matushansky 2009) and consequently of type $e$. If proper names are of type $e$, they cannot combine with a definite article of type $<<\mathrm{e}, \mathrm{t}\rangle, \mathrm{e}>$. Thus, the child (and the linguist) may conclude that the definite determiner can be semantically inert in Greek. Once the determiner has been interpreted as capable of being semantically inert, it is best to assume that ALL instances of the determiner are inert. It then follows that the obligatory presence of articles on proper names is sufficient to trigger a split Def-D structure. This will have repercussions for the possibilities for parametric variation in the DP, which we discuss in Section 5.

\subsection{An aside on the Greek determiner}

In the previous section we proposed to tackle the challenge that polydefinites pose for the encoding of definiteness by suggesting that the definite determiner does not make the semantic contribution that a definite determiner normally makes, namely an iota operator. If it did, we would expect polydefinites to be semantically too POLYdefinite, which they are not. Short of positing ad hoc lexical ambiguity, the solution that the iota operator is contributed by something other than the definite determiner in Greek and languages like Greek seems unavoidable. There are two sets of data which challenge this conclusion. We briefly address these in this section, before we turn to our analysis of polydefinites.

The first set of data, taken from Alexiadou, Haegeman \& Stavrou (2007: 67-68) and ultimately going back to Longobardi (I994: 620), have been used to argue that the definite article contributes referentiality. Example (I7a) features a single definite determiner with coordination below it. As shown by the singular agreement on the verb, the coordinated subject of (I7a) picks out a single referent. By contrast, the coordinated subject of (I7b), with coordination above the definite article, picks out two referents, as shown by the plural agreement on the verb. (This only holds if the DP appears in argument position.) One is thus tempted to conclude that the determiner contributes referentiality.

(I7) (a) Irthe/*irthan o andiprosopos tis dikastikis arxis came.3SG/came.3PL the delegate the.GEN judicial court ke proedros tis eforeftikis epitropis. and chair the.Gen elective committee

'The representative of the court and chair of the elective committee has arrived.'

(b) Irthan/*irthe o andiprosopos tis dikastikis arxis came.3PL/came.3SG the delegate the.GEN judicial court ke $\mathrm{o}$ proedros tis eforeftikis epitropis. and the chair the.GEN elective committee 'The representative of the court and the chair of the elective committee have arrived.' 
However, the purported correlation between number of definite determiners and number of referents is not absolute. As Heycock \& Zamparelli (2000) show, there are languages, for instance English, where coordination below the definite determiner (i.e. the equivalent of (I7a)) CAN involve reference to more than one individual. This is shown in (I8) (from Heycock \& Zamparelli op. cit.: 2, ex. (8)).

(I8) (a) the actor's work depends so much on the technical decisions of [the [director and editor]]

(b) In today's preliminary hearings ... [a [36-year-old farmer and 25-year-old X-ray technician]] both claim a right to asylum.

(c) [My [mouth and throat]] went dry.

In other words, although multiple determiners indeed seem to correlate with multiple referents, a single determiner does not always correspond to a single referent. This means that figuring out the number of discourse referents takes more than simply counting definite determiners. If that is so, then the definite determiner cannot be the sole factor determining the number of referents. According to the proposal put forward by Heycock \& Zamparelli (2000: 7), what is relevant is how pluralities are formed in a given language, with the locus of plurality, PIP, located above NP, and cardinality regulated in NumP, above PIP and below D. (Cross-linguistic variation arises as a result of how different languages treat these functional heads. The interested reader may find details in Heycock \& Zamparelli 2000.)

The second set of data we would like to discuss concerns proper names. As mentioned in the previous section, proper names are taken to be NPs denoting rigidly, thus of type $e$. The Greek D head does not contribute definiteness (see Section 5 for a more detailed discussion). However, there are data, brought to our attention by Dora Alexopoulou (personal communication), which show that proper names can occur without the definite determiner even in Greek, in particular when the proper name occurs in predicative position, as in (I9). This would seem to run counter to our idea that the determiner accompanying proper names is semantically vacuous, since (I9) seems to suggest that its presence (or, more accurately, its absence) is in fact meaningful.

(i9) I Dora den ine Xristina, na vafi ke na stolizi the Dora NEG is Christina subJ paint.3SG and suBJ decorate.3SG pasxalina avga me tis ores.

easter eggs with the hours

'Dora is not like Christina, to spend hours painting and decorating Easter eggs.'

We have been assuming the more or less traditional view, according to which names refer rigidly. Such a theory seems perfectly fit to deal with cases where the proper name appears in argument position, but needs to be supplemented by something in order to deal with predicative uses of proper names. In cases 
such as (I9), what we suggest is going on is a type-shifting operation, whose presence can also be deduced from the marked flavour that examples like (I9) have. The type-shifter involved, much like Partee's (I986) IDENT, takes individuals (type $e$ ) and lifts them to the singleton set containing them (type $<\mathrm{e}, \mathrm{t}>$ ) or to the 'property of being that entity' (Partee 1986: I22). This readily captures the meaning of the article-less proper name in (19), essentially that of a predicate denoting the property of being the individual in question (as the English translation suggests). Possibly, this type-shifter competes syntactically with the definite determiner, or in other words is merged directly with the proper name NP, whence the illicitness of the definite determiner in (I9).

Summing up, we have touched upon the issue of what the definite determiner contributes in a language like Greek, on the basis of two sets of data: one, originally due to Longobardi (1994), suggesting that the definite article contributes reference, and the other, due to Dora Alexopoulou (p.c.), suggesting that the definite determiner is not semantically vacuous with proper names. We have sketched the ways in which these sets of data can be dealt with within the analysis advanced in this paper. Although a comprehensive treatment of definiteness in Greek is beyond the scope of this paper, we hope that future investigations of this topic will be informed by the brief discussion we have engaged in here, and, more generally, by the existence of polydefinites and close appositives alike.

\section{Deriving the properties of close apposition}

Let us now see how the proposal about close apposition can derive the properties of close appositives and polydefinites in Greek. As already mentioned, we propose that polydefinites too consist of two DPs and differ from close appositives only in that an elliptical noun is contained inside the 'adjectival' DP. In Section 2.I in (IO), we gave the tree structure for close apposition in general. The tree structures in (20a) and (20b) provide the ones we propose for polydefinites. The nature and role of ellipsis is the topic of Section 4.I.

(20) (a)

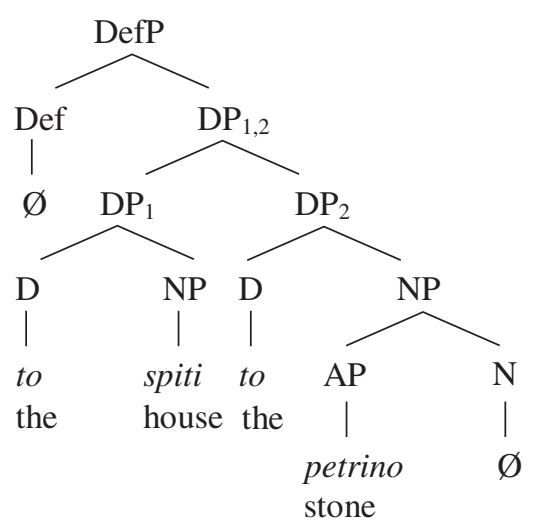


(b)

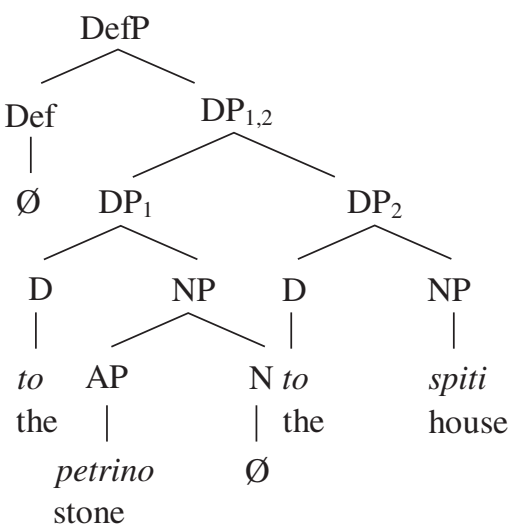

\section{I The ordering freedom}

The ordering freedom displayed by Greek polydefinites and close appositives is consistent with the symmetric structure proposed in (20) above: since neither subpart of close apposition is the head of the construction, no intrinsic ordering exists between the subparts. ${ }^{12}$

It has been noted by a number of authors (Androutsopoulou I995, Alexiadou \& Wilder 1998, Panagiotidis \& Marinis 20II, among others) that polydefinites are possible with more than one adjective (though see Campos $\&$ Stavrou 2004). In that case, all possible word orders are grammatical. ${ }^{13} \mathrm{An}$ example is given in (2I):

(2I) (a) i pena i asimenia i kenurja the pen the silver the new

(b) i pena i kenurja i asimenia

(c) $i$ asimenia i pena i kenurja

(d) i asimenia i kenurja i pena

[12] As Hedde Zeijlstra (p.c.) suggests, another argument in favour of symmetry in the structure of polydefinites comes from the fact that a non-restrictive adjective is illicit in either order:

(i) \#i dilitiriodis $\mathrm{i}$ kobres/\#i kobres i dilitiriodis the poisonous the cobras/the cobras the poisonous

It is of course not the case that this fact is impossible to capture in an analysis that posits asymmetry. The point is that it follows naturally from our proposed symmetric structure.

[13] There does not seem to be complete consensus on the availability of all word orders. For instance, Alexiadou \& Wilder (1998) report that five out of the six orders are possible, whereas according to Campos \& Stavrou (2004), polydefinites are only possible with one adjective, so none of the orders in (22) are possible without intonational breaks. Our speakers, including the Greek native speaker author of the paper, have no trouble with any of the given orders, confirming the judgments reported in Panagiotidis \& Marinis (20II). 
(e) $\mathrm{i}$ kenurja i asimenia i pena

(f) $\mathrm{i}$ kenurja $\mathrm{i}$ pena $\mathrm{i}$ asimenia 'the new silver pen'

For us, this means that there are three DPs in the examples under consideration, and two operations of R-role identification - so, we have here iteration of the binary-branching R-role identification structure. Since the ordering within the close appositive/polydefinite is free, we can (i) permute the order of $\mathrm{DP}_{3}$ with respect to $\mathrm{DP}_{1,2}$, (ii) permute the order within $\mathrm{DP}_{1,2}$ prior to combination with $\mathrm{DP}_{3}$, and (iii) permute the order with which each DP containing an adjective combines with the DP containing the lexical noun. ${ }^{14}$

It has been noted by several authors (see e.g. Panagiotidis \& Marinis 20II) that the ordering freedom of polydefinites is not unconstrained: an adjective (still) has to precede the noun if it is not preceded by a determiner, as shown in $(22)$ :
(a) $* \mathrm{i}$ pena asimenia $\mathrm{i}$ kenurja
the pen silver the new
(b) $*_{\mathrm{i}}$ pena $\mathrm{i}$ asimenia kenurja
the pen the silver new

As Panagiotidis \& Marinis (20II) note, (22a) contains an independently illicit DP, i pena asimenia 'the pen silver'. Recall that in Greek monadic definites, an adjective can never follow a noun. As for (22b), the 'adjectival' DP

[I4] Our derivation of the word order possibilities remains silent on the pragmatic conditions that make some of these orders better suited for particular contexts than others. We believe that, possibly, the parallel with close appositives may be illuminating. The word order variation is, as we expect, also evident here: all possible word orders are grammatical, but context determines which ones will be preferred. Here are two contexts which show different preferred orders of the same elements:

(i) (a) A: Exis gnorisi akomi tin Papadopoulou ti fonologo?

have.2SG met yet the Papadopoulou the phonologist

'Have you met Papadopoulou the phologist yet?'

B: Pja enois? Tin Papadopoulou ti fonologo tin kathijitria who.ACC mean.2SG the Papapopoulou the phonologist the professor $\mathrm{i}$ tin Papadopoulou ti fonologo ti fititria? or the Papadopoulou the phonologist the student 'Who do you mean, Papadopoulou the phonologist who is a professor or Papadopoulou the phonologist who is a student?'

(b) A: Exis gnorisi akomi tin Papadopoulou tin kathijitria?

have.2SG met yet the Papadopoulou the professor 'Have you met Papadopoulou the professor yet?'

B: Pja enois? Tin Papadopoulou tin kathijitria ti simasiologo who.ACC mean.2SG the Papadopoulou the professor the semanticist i tin Papadopoulou tin kathijitria ti fonologo? or the Papadopoulou the professor the phonologist 'Who do you mean? Papadopoulou the professor who is a semanticist or Papadopoulou the professor who is a phonologist?' 
contains an elided noun modified by two adjectives. As Panagiotidis \& Marinis explain, there is an independent ban in Greek on noun ellipsis with more than one adjective when the DP is definite. (Note that there seems to be speaker variation with respect to the ungrammaticality of multiple adjectives under $\mathrm{N}$ ellipsis.)

While adjectival modification within the DP subpart containing ellipsis is subject to restrictions at least for some speakers, modification inside the DP subpart with the overt $\mathrm{N}$ head is possible:

(23) (a) i asimenia i kenurja pena the silver the new pen

(b) i kenuria pena i asimenia the new pen the silver 'the new silver pen'.

This is compatible with our proposal that polydefinites contain two (or more) ordinary full DP subparts..$^{15}$

\subsection{The impossibility of indefinites in close apposition}

Recall that a key property of polydefinites is the absence of polyındefinites, see (24):

(24) (a) ena megalo (*ena) spiti

a big a house

(b) ena spiti (*ena) megalo

a house a big

Note that licensing of the elided noun cannot be the problem with (24), because noun ellipsis is licensed in Greek with indefinite determiners, as well as with no determiner at all (Giannakidou \& Stavrou 1999):

(25) (a) I Maria agorase ena akrivo forema ke the Maria bought an expensive dress and

i Eleni ena ftino.

the Eleni a cheap

'Maria bought an expensive dress and Eleni a cheap one.'

[15] To be precise, there seems to be a prosodic constraint on modification inside the DP with the overt $\mathrm{N}$ head in the sense that the $\mathrm{D}-\mathrm{A}-\mathrm{D}-\mathrm{N}$ order is preferred if the modifier is heavy:

(i) (a) ?*$^{*}[\mathrm{DP} 1,2[\mathrm{DP} 1$ to spiti tu Kosta me tin orea steji][DP2 to megalo]] the house the.GEN Kosta with the nice roof the big

(b) $[\mathrm{DP} 1,2[\mathrm{DP} 2$ to megalo $][\mathrm{DP} 1$ to spiti tu Kosta me tin orea steji]] the big the house the.GEN Kosta with the nice roof

'Kosta's big house withthe nice roof'

We thank an anonymous $J L$ referee for bringing (ia) to our attention. 
(b) I Maria agorazi akriva ruxa ke i Eleni ftina. the Maria buys expensive clothes and the Eleni cheap 'Maria buys expensive clothes and Eleni cheap ones.'

Exactly the same restriction applies in the case of close appositives. As noted by Stavrou (1995), it is not possible for either subpart to be indefinite. In other words, it seems that close apposition (in Greek at least) necessarily involves two definite DPs.
(a) $*_{0} \quad$ Nikos enas kathijitis
the Nikos a professor
(b) *enas kathijitis o Nikos
a professor the Nikos

Our proposal can shed light on this property of close apposition. Recall that in Section 2 we argued that close apposition in Greek involves two DPs as subparts of a larger DP, whose R-roles become identified. This operation involves set intersection, so its input must be of type $<e, t>$. What enables this operation to apply at the level of DP is the fact that, as we have proposed, the Greek determiner does not saturate the nominal category. The Greek definite determiner is not an $<<\mathrm{e}, \mathrm{t}>$,e $>$ type category, rather its semantics is the identity function $\langle\mathrm{T}, \mathrm{T}\rangle$ : its input is identical to its output. It has been proposed independently that the Greek indefinite enas, mia, ena is not the indefinite counterpart of the definite determiner, but a numeral/ quantifier, residing in QP or NumP (see Giusti 1995, Stavrou 2009, and references therein). One argument in favour of this view is the fact that the definite determiner can combine with an indefinite nominal, as in (27a). Note that, in this, the indefinite QP/NumP behaves like other quantified NPs which also can be selected by the definite determiner, see (27b): ${ }^{16}$
(a) $\mathrm{O}$ enas drastis sinelifthi.
the one perpetrator arrested.3SG.NONACT
'One perpetrator was arrested.'
(b) To olo thema mu prokali aidia. the all topic me.GEN causes disgust 'The whole thing disgusts me.'

Now, if the indefinite article is a $\mathrm{Num}^{\circ}$ or a $\mathrm{Q}^{\circ}$, it denotes a generalized quantifier, of type $<<\mathrm{e}, \mathrm{t}>,<<\mathrm{e}, \mathrm{t}>, \mathrm{t}>>$, such that it can take an NP as its argument. The denotation of the NumP is then $<<e, t>, t>$. But this means

[16] For recent discussion of the cross-linguistic interaction between determiners and quantificational elements see Giannakidou \& Etxeberria (20I0) and references therein. We thank an anonymous $J L$ referee for pointing out to us that, barring syntactic restrictions, we expect precisely this kind of 'promiscuity' of our semantically vacuous D. The same referee raises the question of whether, by virtue of its expletive nature, D could not select AP directly. We will not pursue this possibility here. For one thing, on this approach, it is hard to see how the effects that we derive from noun ellipsis (see Section 4 in particular) can be made to follow. 
that indefinite nominals cannot be input to R-role identification, since the operation works with predicative categories of type $<\mathrm{e}, \mathrm{t}>{ }^{17}$

\subsection{The restrictive interpretation}

Finally, we turn to the third central property of close apposition, the restrictive interpretation. To derive this property, we would like to propose that R-role identification does not apply freely, but is subject to a restriction, stated in (28). We think of (28) as an overarching economy condition: applying a complex syntactic operation is only allowed if its output yields an interpretation that is distinct from its input. (See for instance Reinhart 2006 for similar claims.)

\section{Ban on vacuous application of $R$-role identification \\ R-role identification is banned if it yields an output identical to (part of) its input.}

One thing that follows from (28) is that nominals whose R-roles are independently identical cannot form parts of close apposition. This is true. As noted by Stavrou (1995: 225), a close appositive involving a dialectal word and a standard language word for the same object is impossible: ${ }^{18}$

$$
\begin{array}{lll}
*_{i} & \text { sikaminja } & i \text { murja } \\
\text { the blueberry.tree } & \text { DIALECTAL } & \text { the bluberry.tree } \\
\text { STANDARD }
\end{array}
$$

[17] This leaves open the possibility that R-role identification can apply among NP categories. Our semantics for R-role identification certainly permits this. However, it is not clear that this possibility exists. In the realm of polydefinites, a single Def-D structure above two NPs (one of which contains an A modifying a null $\mathrm{N}$ ) that have undergone R-role identification is indistinguishable from a monadic definite containing a single NP; since there cannot exist any positive evidence for this kind of structure, it is ruled out by virtue of being unlearnable. In the realm of close appositives, NP-NP constructs are probably blocked by N-N compounds ('multi word units', see Ralli 1992 for discussion and references). Stavrou (2009) and Velegrakis (20II) explore the idea that polyındefinites do exist in Greek, but they involve 'spreading' of a null indefinite determiner. This would also have repercussions for the domain of application of R-role identification. We cannot properly address this matter here, as it requires consideration of additional parameters, such as the distribution, structure and meaning of bare unmodified nominals (on which see Alexopoulou \& Folli 2010 for recent discussion).

[I8] Note that example (29) involves dialectal words, namely words with different (Fregean) senses and an identical referent. This is not important for the argument presented here, as $* i$ sikaminja $i$ sikaminja is also ungrammatical. Using dialectal words simply helps to highlight the need to posit the ban in (28) for close appositives and polydefinites, both of which, on our analysis, involve R-role identification. Interestingly, this ban in (28) does not hold of identificational copular sentences, which also arguably involve some kind of identity of reference. Compare (29) to the corresponding copular sentence in (i):

(i) I sikaminja ine i murja.

the blueberry.tree DIAL $_{\text {in }}$ is the blueberry.tree STAND $_{\text {Ta }}$

'The blueberry tree [dialectal] is the blueberry tree [standard].'

Evidently, identificational copular sentences are not derived in (exactly) the same way as close appotives/polydefinites. 
To see how the restriction in (28) also derives the obligatorily restrictive interpretation of close apposition, consider again (4), repeated here as (30).

(30)
Idame tis
dilitiriodis
(\#tis)
kobres.
saw.IPL the.PL.ACC poisonous.PL.ACC the.PL.ACC cobras.PL.ACC
'We saw the poisonous cobras.'

The example in (30) is infelicitous as a polydefinite, because all cobras are poisonous and hence the adjective dilitiriodis 'poisonous' cannot receive a restrictive interpretation when applied to kobres 'cobras'. The set of cobras is a subset of the set of poisonous entities: to be a member of the cobra set entails being a member of the poisonous-entities set. In this situation, to identify the R-role of kobres with that of 'poisonous entities' would yield a complex DP with the same denotation as the DP subpart tis kobres 'the cobras'. Therefore R-role identification cannot apply in this case either, because it would involve vacuous complex argument formation.

In sum, constrained by the ban in (28), R-role identification will necessarily yield not just a subset of the intersection of the two sets in question, but a PROPER subset thereof. In Section 4.I we return to the restrictive interpretation of the adjective in polydefinites.

This concludes our general discussion of close apposition, comprising close appositives and polydefinites. In the following section we concentrate on polydefinites, elaborating on what the effects are of noun ellipsis within the 'adjectival' DP and comparing our account to existing alternatives.

\section{Polydefinites Revisited}

In this section we concentrate on the one property that sets polydefinites apart from close appositives, namely the occurrence of noun ellipsis (Section 4.I). We also review alternative analyses of polydefinites (Section 4.2). After a brief consideration of the nature of the ellipsis site in polydefinites, we explore the effects that noun ellipsis has on the interpretation (Section 4.I.I) and on the distribution of adjectives (Section 4.I.2) in the construction. In Section 4.2.I we consider alternative ways of deriving the restrictive interpretation of the adjective. In Section 4.2.2 we turn to the multiple occurrence of the definite determiner. We show that this follows from our analysis, but not from alternative conceptions of polydefinites.

\section{I The role of noun ellipsis}

As mentioned already, our proposal assimilates polydefinites to close appositives, the only difference between the two being that there is a noun ellipsis 
site inside one of the smaller DPs in a polydefinite (see Panagiotidis \& Marinis 20II), as schematically indicated in (3I):
(a) [DP [DP ta spitia ] [DP ta megala Ø]] the houses the big
(b) [DP [DP ta megala $\varnothing][$ DP ta spitia]] the big the houses

We assume that the elided noun is an empty category. This is the position taken in Giannakidou \& Stavrou (1999) for nominal ellipsis in Greek in general (see also Panagiotidis 2003). As Jeroen van Craenenbroeck (p.c.) has pointed out to us, assuming the ban in (28) effectively entails that ellipsis involves a null category and not a full fledged structure that is PF-deleted, since that would incur a violation of the ban in (28) and hence can presumably not be generated. As long as ellipsis involves an empty category, denoting 'entity', then R-role identification may generally take place: when the set of big entities is intersected with the set of houses, the result is the set of big houses, which is not identical to either of the original sets.

An advantage of this view of noun ellipsis is that it explains why ellipsis is obligatory within the polydefinite, i.e. it accounts for the ill-formedness of *to spiti to megalo spiti/*to megalo spiti to spiti 'the house the big house'/ the big house the house'. The problem with these 'non-elliptical polydefinites', so to speak, is that they violate the ban on vacuous application of R-role identification: intersecting the set of houses with the set of big houses will result in one of the original sets, namely the set of big houses. The effect of applying R-role identification is vacuous. Hence the non-elliptical version is impossible. ${ }^{19,20}$

[19] As Giannakidou \& Stavrou (I999: 298) state, a linguistic antecedent is always required when NP ellipsis proper takes place and the semantic interpretation of the ellipsis site is determined by its antecedent. They also show that the antecedent must be the closest available NP (Giannakidou \& Stavrou I999: 308, example (26)). In accordance with this, in polydefinites, the antecedent is the overt $\mathrm{N}$ head present in the complex DP. However, given the syntactic proximity of the antecedent and the anaphor, the semantic interpretation of the anaphor is not recovered from context, but arises through syntactic composition interpreted as set intersection. A similar case can be made for the interpretation of English modified pronouns, such as we the linguists. Here too, the pronoun, which would normally recover its antecedent from the context, is understood to be coreferential with the associate NP the linguists.

[20] As an anonymous $J L$ referee points out, NP ellipsis in Greek satisfies Langacker's (1969) Backwards Anaphora constraint, which prevents an anaphor from simultaneously preceding its antecedent and 'commanding' it, in other words, appearing in a hierarchically higher position (i.e. an anaphor in a matrix clause cannot precede its antecedent in an embedded clause). Note that given our proposed symmetric structure for polydefinites, even in examples like ta megala Ø ta spitia 'the big houses', where the ellipsis site precedes its antecedent, it does not 'command' it. 


\section{I.I Obligatory restrictive interpretation of the adjective in polydefinites}

The restriction in (28) forces a restrictive interpretation within the close apposition, but does not state which subpart of the close apposition has to be interpreted restrictively. In polydefinites, the burden of modifying restrictively (of satisfying the restriction in (28)) obligatorily falls on the adjective (the 'adjectival' DP). Our claim is that this follows from the fact that polydefinites contain ellipsis.

The following set of data, due to Kolliakou (2004: 2I6-2I7), brings out the difference between polydefinites and monadic definites in terms of the obligatorily restrictive interpretation of the adjective in the former but not the latter case. The sentences in (32) and (33) can be felicitously used in any of the situations outlined in $(\mathrm{a}-\mathrm{d})$ below $(32)$, and $(\mathrm{a}-\mathrm{b})$ below (33), respectively. The sentences describing the situations that correspond to a restrictive interpretation of the adjective are set in bold. In the first instance, these data show the more restricted distribution of polydefinites compared to monadic definites.

(32) O Yannis taise ta zoa. I mikres gates itan pinasmenes. the Yannis fed the animals the young cats were hungry 'Yannis fed the animals. The young cats were hungry.'

(a) All the animals Yannis fed were cats, and there were young and non-young cats.

(b) Yannis fed cats and non-cats, and there were young and non-young cats.

(c) All the animals Yannis fed were cats, and there were only young cats.

(d) Yannis fed cats and non-cats, and all the cats were young ones.

(33) O Yannis taise ta zoa. I mikres $i$ gates itan pinasmenes. the Yannis fed the animals the young the cats were hungry

'Yannis fed the animals. The young cats were hungry.'

(a) All the animals Yannis fed were cats, and there were young and non-young cats.

(b) Yannis fed cats and non-cats, and there were young and non-young cats.

As Kolliakou's paradigm shows, the interpretation of polydefinites is different from that of monadics only with respect to the adjective (obligatory vs. optional restrictive interpretation). The noun in polydefinites, just like in the case of the monadic definite, can but need not be restrictive on the previously mentioned noun (i.e. gates 'cats' with respect to zoa 'animals').

The fact that the 'adjectival DP' obligatorily serves as the restrictive term in a polydefinite has to do with the fact that that DP contains noun ellipsis. It is well-established (Williams I997, Giannakidou \& Stavrou I999: 304-305 
specifically for Greek) that in ellipsis contexts non-elided material must be informative (or disanaphoric in Williams' 1997 terms). ${ }^{21}$ This is illustrated in (34):

(34) I Maria forese to ble fustani ke i Eleni forese to the Maria wore the blue dress and the Eleni wore the prasino/\#to ble. green/the blue

'Maria wore the blue dress and Eleni wore the green one/\#the blue one.'

An adjective can fail to be informative if it is (pragmatically) nonrestrictive. In such cases, nominal ellipsis, and likewise the polydefinite, is infelicitous:

(35) (a) O Yannis taise ta mikra zoa. \#Ta mikra the Yannis fed the young animals the young (ta zoa) itan pinasmena.

the animals were hungry

'Yanis fed the young animals. The young ones/animals were hungry.'

(b) Edo de tha vris kobres. \#I dilitiriodis here NEG FUT find.2SG cobras the poisonous

(i kobres) zune alu.

the cobras live.3PL elsewhere

'You won't find any cobras here. The poisonous ones/cobras live elsewhere.'

In brief, the polydefinite shows the effects of (28)-restrictive interpretation - by virtue of being an instance of close apposition, i.e. by virtue of involving an operation constrained by (28). The fact that it is always the adjectival DP that needs to meet the requirement in (28) follows from the fact that the adjectival DP contains structure that independently imposes a requirement of restrictive interpretation.

\section{I.2 Distribution of adjectives and adjective interpretations}

As we saw in the previous section, on our account, the restrictive interpretation of the adjective follows from the noun ellipsis site posited in

[2I] The fact that this is a discourse requirement is supported by the fact that (34) would not be infelicitous if the noun fustani 'dress' was not elided. It would simply be strange: as a consequence of uniqueness, the most readily available reading of the sentence would be that Maria and Eleni wore the same blue dress. 
polydefinites. This component of their structure makes for a more general statement on the distribution of adjectives in polydefinites: all and only the set of adjectives that can appear in noun ellipsis contexts will be licit in polydefinites. This is indeed the case. In this section we briefly make this point.

It has been noted by a number of authors (e.g. Alexiadou \& Wilder 1998, Alexiadou 200I) that so-called thematic (i.e. relational and ethnic) adjectives and adjectives in proper names are ungrammatical in polydefinites. The following examples illustrate this claim for relational adjectives and adjectives in proper names:

(36) i piriniki (*i) enerjia the nuclear the power 'the nuclear power'
o Notios $(* 0)$ Polos
the South the Pole
'the South Pole'

Crucially, such adjectives are also impossible in noun ellipsis contexts:

(38) o ekdotikos *(ikos)

the publishing house

'the publishing house'

(39) Kita tin idrojio. Aftos ine o Vorios Polos

look.IMP.2SG the globe this is the North Pole

ke ekinos ine o Notios *(Polos).

and that is the South Pole

'Look at the globe. This is the North Pole and that is the South Pole/ *one.'

Following Alexiadou \& Wilder (1998) and Alexiadou (200I), we assume that relational adjectives form a compound with the noun they modify (see also Ralli \& Stavrou I998). This suffices to rule them out in polydefinites. Ralli \& Stavrou (1998) provide several arguments to the effect that relational adjectives form a (syntactic) compound with the noun they modify (an A-N construct, in their terminology), in the sense that the adjective does not behave like an independent syntactic head, but rather forms a unit with the noun. For example, Ralli \& Stavrou (op. cit.) observe that such adjectives cannot be conjoined, modified, extended or complemented, and that in indefinite DPs the order of the adjective with respect to the noun is fixed (unlike the case of adjectives in indefinite DPs in general). It is then hardly surprising that these constructs cannot give rise to polydefinites. On the other hand, what we do expect is for these collocations to occur in a polydefinite as the (lexically realized) nominal subpart, and this is indeed the case. Note that examples such as (40a) cannot be taken to involve attributive modification inside this nominal 
$\mathrm{DP}$, since re-ordering of the adjectives, which is otherwise possible in the polydefinite (see (4I)), is impossible in this case, as shown in (40b):

(40) (a) o diasimos o ekdotikos ikos the famous the publishing house 'the famous publishing house'

(b) *o ekdotikos o diasimos ikos the publishing the famous house

(4I) (a) to megalo to kokino podilato the big the red bicycle

(b) to kokino to megalo podilato the red the big bicycle 'the big red bicycle'

A different restriction has to do with certain adjectives that are normally (i.e. in monadic definites) ambiguous between an intersective and a nonintersective reading. These adjectives only have the intersective reading in polydefinites (Alexiadou 200I, Campos \& Stavrou 2004). The same reading is the only one which survives when there is nominal ellipsis (see Branco \& Costa 2006 for this observation based on Romance) ${ }^{22}$

(42) (a) Gnorises tin orea tin tragudistria?

met.2SG the beautiful the singer

'Did you meet the beautiful singer?' (intersective only)

(b) Gnorises tin orea tragudistria?

met.2SG the beautiful singer

'Did you meet the beautiful singer?' (intersective and nonintersective)

(c) Gnorises tin orea?

met.2SG the beautiful

'Did you meet the beautiful one?' (intersective only)

Connected to the lack of non-intersective readings in polydefinites, it seems to be generally the case that non-intersective adjectives are ruled out in polydefinites (Kolliakou 2004). Again, this is also observed in the case of nominal ellipsis:

(43) (a) i ipotithemeni $\left({ }^{*} \mathrm{i}\right)$ tromokrates the alleged the terrorists

(b) $*_{\mathrm{i}}$ ipotithemeni the alleged

However, at least for some speakers, it is possible to contextually force an intersective interpretation even on non-intersective adjectives, to the effect

[22] Note that (42c) is meant to involve NP ellipsis. Thus, native speakers of Greek should judge it in a felicitous discourse context, such as when a set of dancers has been previously mentioned. 
that such an adjective can receive a restrictive interpretation and thus appear in a polydefinite. Leu (2007) notes that (44), his (25), is acceptable for some speakers in an appropriate context.

(44) O PROIGUMENOS o prothipurgos pethane. the previous the prime.minister died

'It is the previous prime minister that died.'

The sentence in (44) is licit in a context where the speaker corrects another interlocutor (hence the heavy stress on the adjective, marked by capitals), who thinks she has overheard that the current prime minister is dead. What makes the polydefinite available is that a mention of the current prime minister in the previous discourse makes the set of all-time prime ministers salient, and it thus becomes possible to construct different subsets of this set, of which the polydefinite picks out a proper subset. In other words, in the case of those non-intersective adjectives that are licit in polydefinites, the context plays a crucial role in providing the superset in a salient and explicit way. Crucially, and as expected within our analysis, in this context the equivalent of the polydefinite with just noun ellipsis is also possible:

\section{(45) O PROIGUMENOS pethane.}

the previous died

'It is the previous one that died.'

This set of data is important because such data allow us to compare the approach advocated here with a widespread view of polydefinites, which relies on the idea that they involve a subject-predicate structure. On such a predicative conception of (the derivation of) polydefinites, the adjectives that can appear in the construction are all and only the adjectives that can appear in the predicate position of a copular sentence (see Alexiadou \& Wilder 1998, Alexiadou 200I, Campos \& Stavrou 2004, Ioannidou \& den Dikken 2009, Panagiotidis \& Marinis 20II). The predicative approach goes a long way in deriving the set of admissible adjectives - it can capture the cases discussed so far - but it fails in this instance. As we just saw, in some cases non-intersective adjectives are possible in the polydefinite. However, they remain impossible in a main clause predicate position: $:^{23}$

(46) *Aftos o prothipurgos itan PROIGUMENOS. this the prime.minister was previous

[23] David Adger and Michael Brody suggest independently, in personal communications, that one could combine our idea that polydefinites involve nominal ellipsis with a predicational analysis. In other words, the underlying structure of polydefinites would still involve predication, but the predicate position is occupied by a DP of the sort we propose, i.e. one containing adjectival modification of an empty noun. That would still not answer the question of why (46) is ungrammatical, i.e. why this elliptical DP is available only in the predication structure involved in polydefinites but not as a main clause predicates. 
Another set of data that undermine the relevance of predication involves the adjective alos 'different/other', which can happily occur within the polydefinite but not in post-copular position, see (47):

(47) (a) $\mathrm{i}$ ali i singrafeas

the other the author

'the other author'

(b) $*_{\mathrm{i}}$ singrafeas ine ali

the author is other

For an overview of such mismatches, see Alexiadou (2006).

To sum up, positing noun ellipsis inside the polydefinite derives not only the obligatorily restrictive interpretation of the adjective, but also the set of adjectives (and adjective interpretations) that are possible in the construction. This set includes, under certain circumstances, adjectives that are illicit in predicative position. This argues against analyses that assume that, underlyingly, a predication relation exists between the noun and the adjective in polydefinites. In the next section we discuss such alternatives in some more detail. We will be especially concerned with how they derive the obligatory restrictive interpretation of the adjective and how they account for the definiteness puzzle that polydefinites pose, namely, the multiple realization of the definite determiner that is only interpreted once.

\subsection{Comparison with alternative analyses of polydefinites}

In this section we discuss alternative analyses of polydefinites and focus in particular on how they deal with two properties of the construction: the restrictive interpretation and the occurrence of multiple determiners.

\subsection{Alternative accounts of the restrictive interpretation}

In our account, the restrictive interpretation of the adjective is a consequence of the requirements that noun ellipsis, contained in the 'adjectival DP', independently poses. There are at least two alternatives available: the one due to Kolliakou (2004), and one relying on the existence of a DP-internal Focus projection.

Kolliakou proposes that polydefinites are subject to the following constraint:

(48) Polydefiniteness constraint (Kolliakou 2004: 273)

Greek polydefinites are unambiguously non-monotone anaphoric expressions: the discourse referent $\mathrm{Y}$ of a polydefinite is anaphoric to an antecedent discourse referent $\mathrm{X}$, such that $\mathrm{Y} \subset \mathrm{X}$. 
The constraint in (48) is meant to account for the contextual restrictions on polydefinites illustrated above, in (32) and (33). We believe that it may well do that, but it does not capture the restrictive interpretation of the adjective. First consider how (48) works. In the context Yannis taise tis gates 'Yannis fed the cats', the discourse referent which serves as the antecedent for the polydefinite $i$ mikres $i$ gates 'the young cats' is the set of cats. For the polydefinite to denote a proper subset of that set, there have to be young and non-young cats (restrictive adjective). If there are only young cats (nonrestrictive adjective), the polydefinite fails to be anaphoric in the way prescribed by (48). Now consider a slightly different context (in fact Kolliakou's original one, namely the one used in (32) and (33) above), $O$ Yannis taise ta zoa 'Yannis fed the animals'. In this context the polydefinite $i$ mikres i gates can satisfy the constraint in (48) even if the set of cats itself does not include any non-young ones, i.e. without the adjective being interpreted restrictively. This is because in this particular context, the nominal itself can suffice to satisfy (48), since cats are a proper subset of the set of animals (i.e. whenever there are non-cats in the set of animals). In other words, in this particular context, the polydefinite can satisfy the constraint in (48) even on the non-restrictive interpretation of the adjective. This makes the wrong prediction, that adjectives in the polydefinite can be freely interpreted non-restrictively.

A popular alternative is that the restrictive interpretation of the adjective in the polydefinite is due to the fact that the adjective is focused (see e.g. Kariaeva 2004, Ntelitheos 2004, Leu 2007, and many others). However, there are theoretical and empirical problems with this position. As Szendröi (20I0) argues, it is theoretically impossible to think of a focusbackground partitioning DP-internally, as such notions are intrinsically propositional. For us the adjectival part is not obligatorily focused, it is just non-anaphoric, just as the noun ellipsis account we have been pursuing predicts. Focus and disanaphora/non-givenness are not two sides of the same coin (Krifka 2006, Reinhart 2006, and also Neeleman \& Szendrői 2004, Féry \& Samek-Lodovici 2006; contra Schwarzchild 1999 and much subsequent work).

On the empirical side, as noted by Kolliakou (2004: 276), the whole polydefinite itself can have discourse functions other than focus. For instance, in (33) above, repeated in part as (49a) below, $i$ mikres $i$ gates 'the young the cats' is most likely a contrastive topic. ${ }^{24}$

Even more crucially, it can be shown that it is prosodic prominence, whenever present, not polydefinite syntax, that induces the

[24] Following for instance Büring (2003), we believe that the grammatical distinction between focus and contrastive topic is real, but note that some authors, such as Roberts (I996) and Williams (1997), treat contrastive topics as a subtype of focus. 
exhaustivity/contrastivity effects usually associated with focus. Compare (49a) to (49b):

(49) (a) O Yannis taise ta zoa. I mikres $i$ gates itan the Yannis fed the animals the young the cats were pinasmenes, opos episis ke i megales (i gates). hungry, as also and the big the cats 'Yannis fed the animals. The young cats were hungry, and so were the old ones.'

(b) O Yannis taise ta zoa. I MIKRES i gates itan the Yannis fed the animals the young the cats were pinasmenes, \#opos episis ke i megales (i gates). hungry, as also and the big the cats 'Yannis fed the animals. \#The YOUNG cats were hungry, and so were the old ones.'

The examples in (49) differ only in that in (49b) the adjective inside the polydefinite bears (contrastive) stress. What (49) shows is that it is not the polydefinite per se that comes with what has been seen as the hallmark of focus, namely an exhaustive interpretation, since (49a) is perfectly well-formed even if it contains a continuation that is incompatible with an exhaustive interpretation. On the other hand, the variant of (49a) with stress on the adjective, namely (49b), is pragmatically infelicitous because the cancellation of the exhaustive interpretation is at odds with the interpretation forced by stressing the adjective. In other words, it is stress that incurs the effects of focus, and not the polydefinite construction in and of itself.

\subsubsection{What's in a definite article?}

Finally, let us turn to the issue of the multiple occurrences of the definite determiner.

In the analysis we have advanced in this paper, polydefinites are an instance of close apposition, which, given the nature of D in Greek, can take place between DPs. Specifically, we have argued (see Section 2.2 above) for a split between Def, which is the locus of semantic definiteness, and D, which is the morphosyntactic manifestation of definiteness in Greek. This split is not specific to polydefinites, rather it is a general feature of Greek definite DPs, including monadic ones. In considering the existing alternative approaches to our proposal, we identify a common problem with all of them: an explanation for the multiple occurrence of the definite determiner in polydefinites is lacking. We will first review some of the existing alternative analyses and then elaborate on the intepretative problem that arises and fails to be satisfactorily addressed. 
A popular idea has been that polydefinites underlyingly involve a predication structure (e.g. Alexiadou \& Wilder 1998, Campos \& Stavrou 2004, Ioannidou \& den Dikken 2009, Panagiotidis \& Marinis 20II). Let us review such predicative analyses in turn.

Consider, for example, Alexiadou \& Wilder's (1998) analysis. These authors propose that the underlying structure of polydefinites involves a Kaynean-style relative clause, whose subject is itself is a DP rather than an NP. This base structure is given in (50a). The D-A-D-N order is derived as shown in (5ob): 'predicate raising' takes place and moves the AP to [Spec, $\mathrm{CP}$. The D-N-D-A order is derived by an additional (optional) step of DP raising to $[\mathrm{Spec}, \mathrm{DP}]$, as shown in $(5 \mathrm{Oc})$.

(50) (a) [DP the D [CP [IP [DP the book] [AP red]]]]

(b) [DP the D [CP [AP red] [IP [DP the book] $\left.\left.\left.\mathrm{t}_{\mathrm{AP}}\right]\right]\right]$ ('predicate raising')

(c) [DP [DP the book] the $\mathrm{D}\left[\mathrm{CP}\left[\mathrm{AP}\right.\right.$ red] [IP $\left.\left.\left.\mathrm{t}_{\mathrm{DP}} \mathrm{t}_{\mathrm{AP}}\right]\right]\right]$

(DP raising to SpecDP)

The occurrence of multiple determiners is 'baked into' the analysis, in that by assumption the subject of the reduced relative clause is a DP, and not an NP, as in Kayne's original work. However, this crucial departure from the Kaynean analysis is not independently motivated; and if it is meant as a general proposal for relative clauses, then we expect determiner spreading to be much more prevalent cross-linguistically than it actually is. ${ }^{25}$ Moreover, if we were to single out one determiner that would be responsible for the unique interpretation of the whole DP, that would not be the same one across (50): in (50a) and (5ob) it would be, presumably, the CP-external definite article contributing definiteness, while the lower one would be vacuous; but in (50c) what contributes definiteness cannot be the CP-external determiner, but rather the one that surfaces/scopes over it. ${ }^{26}$

[25] Although the existence and nature of Greek reduced relative clauses seems ill-understood at this point, as long as structures such as (i) constitute relevant instances, they seem to require an indefinite subject, rather than a definite one. This argues against assimilating reduced relative clauses to polydefinites. We thank Lila Daskalaki (p.c.) for providing the examples and discussing them with us.

(i) (a) ena/*to arthro grameno sto podi a the article written on.the foot 'a hastily written article'

(b) $\mathrm{mia} /{ }^{*} \mathrm{i}$ istoria vgalmeni apo ti zoi a/the story taken from the life 'a real-life story'

For discussion of the post-nominal order of indefinitely modified NPs in Greek (featuring adjectives, not participles), see Stavrou (1996) and Alexiadou (200I).

[26] Similarly to Alexiadou \& Wilder (1998), Panagiotidis \& Marinis (20II) also propose that polydefinites involve predication, albeit in a small-clause structure; similarly to us, for these authors too polydefinites involve two DPs, one of which contains noun ellipsis. As a result, like us, they can also account for the presence of multiple determiner(s). As far as the 
An additional point concerns the case of the DP subject inside the relative clause. If there is a relative clause inside polydefinites, containing a subjectpredicate structure, we would perhaps expect the subject of predication to always show up with nominative case. But, as already noted in the introduction (see especially fn. 5), the two DP subparts in a polydefinite carry the same case: the one assigned to the polydefinite by the selecting head, see (5I). One could perhaps try to analyse this as an instance of case attraction to the relative clause predicate. But as (52) illustrates, case attraction in relative clauses may only affect the relative pronoun; it never affects the predicate of the relative clause.

(5I) Ixa tin taftotita sti dermatini tin
had.ISG the.ACC identity.card in.the.ACC leather the.ACC
tsanda mu.
bag me.GEN
'I had identity card in my leather handbag.'

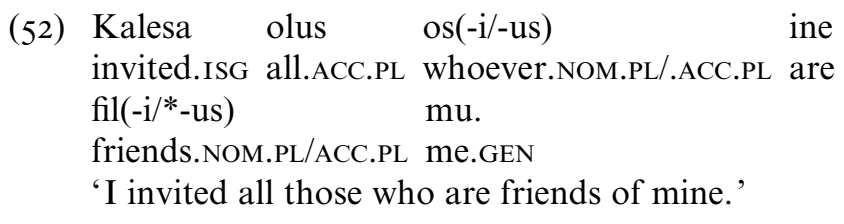

Thus, overall, it seems that an analysis that assumes full clausal predication inside the polydefinite faces various problems. First, the occurrence of multiple determiners is not actually derived, and positing multiple $\mathrm{D}$ heads does not match the interpretational facts. Secondly, case sharing between the two nominal parts is unexpected.

According to Campos \& Stavrou (2004), one of the determiners in polydefinites realizes the $\mathrm{D}$ head, while the other is the phonological instantiation of a different functional head, Pred, which is itself responsible for introducing the predication. In particular, these authors propose that (53) is the structure of the $\mathrm{D}-\mathrm{N}-\mathrm{D}-\mathrm{A}$ order of polydefinites.

(53) [DP the $\operatorname{pen}_{\mathrm{D}}\left[\mathrm{FP}\left[\mathrm{PredP}\right.\right.$ pro the $e_{\text {Pred }}[\mathrm{AP}$ silver]]]]

(Campos \& Stavrou 2004: 157)

In (53), the nominal head of the construction is base generated under D (forming a complex head with the determiner), while the head of the small clause-like PredP is by assumption another determiner. But no independent motivation is provided as to why this Pred head should take the form of the

interpretation of definiteness is concerned, however, their analysis faces the same criticism as the one facing the analysis of Alexiadou \& Wilder. Furthermore, on this proposal, one $\mathrm{DP}$ is the subject and the other is the predicate of the small clause. In the D-N-D-A order, the 'adjectival' DP is the predicate, whereas in the $\mathrm{D}-\mathrm{A}-\mathrm{D}-\mathrm{N}$ order, it is the subject of predication. But this difference is not motivated. 
definite determiner. Thus], although this analysis fares better with respect to case distribution, the syntactic and semantic import attributed to the 'adjectival' determiner make it substantially different from the 'regular' determiner found in monadics, without this move being independently motivated.

For Ioannidou \& den Dikken (2009) the basic structure is as in (54), with the definite article occupying the lower, Deixis (Dx) head.

\section{(54) $\left[\mathrm{DP} \mathrm{D}\left[\right.\right.$ FocP Foc $\left[\mathrm{Dxp}\right.$ Dx $\left.\left.\left.{ }^{\text {PERSON }}[\ldots \mathrm{N} \ldots]\right]\right]\right]$}

Following Pesetsky \& Torrego's (200I) proposal concerning T-to-C movement, Ioannidou \& den Dikken assume that the higher head, D, is phonologically empty unless Dx raises to it. (In cases where FocP is projected, Dx first raises to Foc.) But departing from Pesetsky \& Torrego, they assume that in case Dx-to-D raising occurs, the phonological shape of $\mathrm{D}$ is identical to that of Dx; this merits an explanation. Abstracting away from the further specification of the particular spell-out mechanism the authors rely on (which the interested reader can find in Ioannidou \& den Dikken 2009: 398), this is how polydefinites end up with 'extra' determiners. As no independent motivation is given for the assumption that head raising would result in identical phonological forms in the Dx and the Dx-D positions (as well as the Dx-Foc-D position), in our view, the proposal fails to provide an explanation for the multiple instantiation of the definite determiner in polydefinites.

A different kind of approach is pursued by Kariaeva (2004), following Androutsopoulou (1995). In many respects more akin to our own proposal, she provides an analysis of polydefinites in a split-DP framework without assuming predication. To be precise, Kariaeva assumes that the Greek DP is split into a DeicticP and a DP with an additional FocusP sandwiched between the two, as in (55).

\section{(55) [DeicticP [FocP [DP [NumP [NP ] ]]]]}

Kariaeva assumes that AP modifiers can be base generated at a high (FocP) or low (NumP) functional position within the DP. If an AP modifier is basegenerated low, it will enter into an agreement relationship with the $\mathrm{N}$ in terms of number and gender agreement. However, if a modifier is introduced high, i.e. in the FocP above DP, then it has to enter an agreement relation with the DP, and so it will show definiteness agreement with the DP alongside gender and number agreement. According to Kariaeva, this gives rise to a phonological copy of the definite article on the modifying adjective. This is how the presence of the extra determiner is accounted for. However, no independent argument is offered to support the assumption that high attachment of the adjectival modifier would trigger definiteness agreement on the adjective. Therefore, in effect, the account stipulates the existence of 
polydefinites, rather than explains it. ${ }^{27}$ More importantly, Kariaeva's analysis is asymmetric in the sense that the multiple instantiations of the definite determiner have different roles: the one on the noun is a semantically and syntactically genuine article, while the ones on the adjectives are just phonological copies. But, as we argued in Section 2.2, neither overtly realized determiner seems to be semantically genuine: the scope of definiteness in the polydefinite is in the intersection of its two subparts, not in the positions where the determiners surface.

In all, it seems to us that no existing account fares well with respect to deriving the occurrence of multiple determiners. What is more, the (implicit or explicit) claim of the above analyses is that one occurrence of the determiner is semantically real, while the others are either semantically expletive or realizations of distinct syntactic heads. What this amounts to is that the Greek definite determiner comes in two guises, one in which it contributes semantic definiteness and one where it does not. Monadic DPs involve the former; polydefinites involve one instance of the former and several instances of the latter. But no independent justification is given for positing this lexical ambiguity or its specific distribution.

In contrast, the multiple occurrence of determiners falls out from our close appositive analysis, since polydefinites, as an instance of close apposition, involve definite DPs as subparts. Given our treatment of definiteness in Greek, which is grounded in the obligatory occurrence of determiners with proper names, no occurrence of the definite determiner is actually responsible for the semantic effect. Since the locus of semantic definiteness is not D, but Def, and since that holds in monadics as well as polydefinites, we do not need to rely on lexical ambiguity of D. The split Def-D structure of Greek definite DPs also makes our proposal immune to a criticism on the grounds of semantic compositionality.

\section{BEyond GREEK: ON THE CROSS-LINGUISTIC (UN)AVAilability OF POLYDEFINITES}

In the previous sections we developed an analysis of polydefinites and close appositives in Greek. We argued that the language has expletive determiners, which allows for the construction of a symmetric, complex DP with R-role

[27] The analysis of Kolliakou (2004) faces problems that are in important respects similar to those facing proposals that involve a split DP. Her Head-driven Phrase Structure Grammar (HPSG) framework allows an elegant solution to the problem that multiple instances of the determiner in a single DP give rise to a single definite meaning. But her assumption that, phonologically, any $\mathrm{N}$ or $\mathrm{A}$ head can occur with a clitic-like determiner is not independently motivated. She notes a parallel with the genitive clitic, which indeed enjoys a relative freedom of placement within the DP. But crucially, genitive clitics cannot be doubled. Thus, the fact that determiners can be doubled is not independently motivated in her analysis either. 
identification. This gives rise to close apposition. Polydefinites have the same structure, with the additional difference that one of the DP subparts involves noun ellipsis. We showed that this analysis is successful in deriving the core properties of the construction (freedom of word order, restrictive nature of the adjectives and inapplicability for indefinite DPs). We also showed that our analysis fares better than existing alternatives at least with respect to the multiple occurrence of the definite determiner, and the discourse status of the adjective.

Here we would like to go a step further, and raise an issue which, to the best of our knowledge, has thus far not been duly addressed: Why is it that Greek, but not, say, English, German, French or Italian, has polydefinites? We would like to propose that there are three separate parameters which have to have the right value for polydefinites to be possible (see Lekakou \& Szendröi in press). First, for reasons we discuss presently, the language must make extensive use of morphological case marking. This means that case marking must affect all nominals, and not just pronouns. Second, as we already discussed in Section 5.2, the language must have articles appearing obligatorily on proper names. It is only if both conditions are met that the language may have complex DPs that give rise to close appositives of the Greek type. Third, given that we analyse polydefinites as close appositives involving noun ellipsis, the language must additionally allow noun ellipsis, if it is to have polydefinites. In what follows, we will concentrate on the first two parameters. ${ }^{28}$ Thus, we will talk about a four-way typology: languages that have both morphological case and obligatory determiners on proper names (Greek), languages that have morphological case but no obligatory determiners on proper names (e.g. Standard German), languages that have determiners on proper names, but no morphological case marking (e.g. Catalan), and languages that have neither (English).

\section{I Creating arguments and marking them as such}

Thus far our discussion has been based on the assumption that nominal predicates must be turned into type $e$ in order to be able to act as arguments of the clausal predicate. It is standardly assumed (by Longobardi I994, Szabolcsi 1994, and others) that the definite article is responsible for this, but we have argued that this is not always the case, in view of languages like Greek, where the head that saturates the nominal is not phonologically overt D but phonologically null Def.

[28] We thus, in principle, do not rule out polydefinites that involve some kind of overt dummy noun like English one instead of noun ellipsis. However, if, as we argue, one of the conditions for polydefinites is the availability of morphological case, then such cases might be hard to find, given that languages with morphological case tend to also allow noun ellipsis. 
In addition, we assume that argument nominals must be syntactically marked as such to be visible for the clausal predicate (see Bittner \& Hale I996, Neeleman \& Weerman 1998). We implement this by assuming that a syntactic feature, [+arg]umental, is hosted on the highest nominal projection of an argumental NP. This makes the nominal accessible to the clausal predicate. Since there is no semantics attached to this feature, the denotation of the node bearing it, if it projects on its own, is of type $<\mathrm{e}, \mathrm{e}>$ : the element bearing it takes argument nominals and marks them as such. We further assume that the head hosting $[+\arg ]$ must be phonologically overt. This is because it is semantically empty and its function is to mark the argument as such for the syntax. Assuming a semantically and phonologically empty category with syntactic function would be unfalsifiable and unlearnable.

Traditionally, the bearer of $[+\arg ]$ is case (Bittner \& Hale 1996, Neeleman \& Weerman 1998; Öztürk 2005, and in fact GB Visibility Condition (Chomsky I986: 94)). However, because of our assumption that the bearer of $[+\arg ]$ needs to have phonological content, this will only apply in a language that has morphological case, i.e. only when the functional head Kase is active and thus capable of hosting [ $+\mathrm{arg}]$. We thus depart from earlier proposals in that we do not assume that Kase, usually abbreviated as $\mathrm{K}$, is always projected as a distinct functional head. In our view, if there is insufficient positive evidence available to the language-learning child for projecting an independent syntactic $\mathrm{K}$ (ase) head to host morphological case, i.e. when there is no morphological case on nominals, $\mathrm{K}$ (ase) will not be projected separately from other functional heads, such as $\mathrm{D}$, for instance. In that situation, the [ $+\arg ]$ feature will be hosted by the D head, as long as it is the highest functional head in the nominal projection that has phonological content. This gives rise to the 'impression' that it is the definite article per se that allows for the nominal to be theta-marked, as in (56) (see Longobardi I994): $: 29,30$

$[\mathrm{NP}]]$

$$
+\arg
$$

Our proposal receives empirical support from the WALS typological database (Haspelmath et al. 2005). A series of searches revealed that

[29] For related discussion on the relation between K(ase) and D, see e.g. Löbel (I994) and Giusti (1995). According to Neeleman \& Weerman (1998), the projection of a separate K head is determined by Universal Grammar. Assuming that a separate K head must be projected in every language of course solves the learnability problem posed by a semantically inert and phonologically empty element functional head K. Nevertheless, we do not endorse this proposal, but rather assume that $[+\arg ]$ needs to be hosted by the highest phonologically overt functional projection of the noun phrase. In languages with morphological case, this head is indeed $\mathrm{K}$.

[30] Conversely, in languages lacking definite articles, it can be argued that it is Kase that renders nominal predicates arguments (see Öztürk 2005 for Turkish), and at the same time marks them as such. 
languages are either head-marking or have morphological case, (and/)or obligatory definite articles or obligatory classifiers. Thus, in dependentmarking languages, either Kase and/or D or Class is overtly realized. We propose that the highest active head hosts $[+\arg ]$, which is in turn responsible for rendering the argument visible for the clausal predicate. ${ }^{31}$

\subsection{The role of morphological case and its interaction with definiteness}

We can now turn to how the encoding of definiteness, ultimately the (un)availability of polydefinites, depends on the (un)availability of Kase in a given language. Recall that, on our proposal, the existence of polydefinites in a language requires that language to have expletive determiners, i.e. a split Def-D system. Putting aside languages without definite articles for the moment, for the reason that our interest is in the multiple realization of definite articles, the following typology emerges:

(57) Language with morphological case:

$$
\begin{aligned}
& {[\mathrm{K}} \\
& +\arg
\end{aligned}
$$

Language without morphological case: [D ... [NP]]

$$
+\arg
$$

Languages where both case and definiteness are projected as separate functional layers may involve a split or non-split DP:
(a) $[\mathrm{K}$
$\left.\left[\begin{array}{ll}\mathrm{D} & {[\mathrm{NP}}\end{array}\right]\right]$
$+\arg$
(b) $\left[\mathrm{K} \quad\left[\mathrm{Def}_{\varnothing}[\mathrm{D}[\mathrm{NP}]]\right]\right.$ $+\arg$

Crucially, the possibility for a split Def-D structure is dependent on the presence of a D-type head DIsTINCT from Kase. Recall that, by assumption, a phonologically empty head is unable to support $[+\arg ]$, a feature that is purely syntactic and receives no semantic interpretation. Thus, Def (in Greek, for example) can never bear [ $+\mathrm{arg}]$. This impossibility is schematized in (59):

$$
\begin{aligned}
& *\left[\operatorname{Def}_{\varnothing}[\mathrm{D} \quad[\mathrm{NP}]]\right] \\
& \quad+\arg
\end{aligned}
$$

[3I] This is not to say that predicates never receive case marking. In Greek, for instance, nominal categories in predicative position bear case. But as the example in (i) suggests, this is case agreement between subject and predicate, and not case assignment to the predicate. See Matushansky (2009) for discussion and references.
(i) Theoro to Jani eksipno.
consider.ISG the Janis.ACC clever.ACC
'I consider Janis clever.' 
At the same time, the $[+\arg ]$ feature must be hosted by the highest head in the nominal functional projection in order for the nominal to be visible from outside of its projection. This means that a Def-D split is impossible unless a higher, overt head, to bear [ + arg] (such as the head of KaseP), is projected. We thus predict that languages with a Def-D split are necessarily languages with morphological case (but not the other way round).

\subsection{Typological possibilities}

Given this set-up, the following four-way typology of languages emerges: a language may have morphological case and obligatory determiners on proper names (e.g. Greek, Bavarian); a language may have morphological case, but no obligatory determiners on proper names (e.g. Standard and Northern German); a language may lack morphological case, but have determiners on proper names obligatorily (e.g. Catalan and certain Northern varieties of Italian); and, finally, a language may lack both morphological case and determiners on proper names, such as English. We will examine each language type in turn and demonstrate how our analysis accounts for both proper names and common nouns. Given this typology, our prediction is that only languages of the first type allow polydefinites. This is because polydefinites depend on the presence of expletive determiners in the language, giving rise to a split Def-D structure, which in turn depends on the presence of morphological case.

A child learning Greek quickly establishes that the language has morphological case marking. Case marking is apparent on nouns, determiners and even adjectives, and it is reportedly acquired very early (Marinis 200I). As a result, the child will assume that a separate Kase projection is present in the nominal extended projection. The child also realizes that proper names take determiners obligatorily; there is no semantic or pragmatic feature such as familiarity associated with the determiners on proper names, determiners are simply obligatory. This means that the child has positive evidence to distinguish semantic definiteness from the phonologically realized D head. She will thus assume that the overt realization of the definite article is semantically inert. Semantic definiteness is encoded on a separate projection. As outlined in Section 2.2, the semantic type of the D head itself is the identity function: whichever type is its input will also be its output.

(60) Type I: Morphological case and obligatory determiners on proper names

$\begin{array}{cccc}{[\text { Kase }} & {[\text { Def }} & {[\mathrm{D}} & \left.\left.\left.\left[\mathrm{NP}_{\text {Common Noun }}\right]\right]\right]\right] \\ <\mathrm{e}, \mathrm{e}> & <<\mathrm{e}, \mathrm{t}>\mathrm{e}\rangle & <\mathrm{T}, \mathrm{T}> & <\mathrm{e}, \mathrm{t}> \\ {[\text { Kase }} & {[\mathrm{D}} & \left.\left.\left[\mathrm{NP}_{\text {PROPER NAME }}\right]\right]\right] \\ <\mathrm{e}, \mathrm{e}> & <\mathrm{T}, \mathrm{T}> & \mathrm{e}\end{array}$

The same state of affairs applies in Bavarian. Here too, morphological case and the obligatoriness of the definite article on proper names gives rise to 
polydefinites. This is illustrated by the Bavarian equivalent of Kolliakou's by-now-familiar example (Susanne Höfler, Theresia Höfler, Veronika Habler p.c.) in (6I):

(6I) Da Hauns hot die Kotzn gfuatat. Die Kotzn die jungen hom the Hans has the cats fed the cats the young.PL have an bsundan hunger ghobt.

a real hunger had

'Hans fed the cats. The young cats were really hungry.'

Just like his or her Bavarian 'cousin', a child learning Standard German will posit separate $\mathrm{K}$ and $\mathrm{D}$ heads to host morphological case and the definite articles respectively. But since there is no evidence for a split D structure in the form of obligatory articles on proper names, the child will be content with a structure that projects one functional layer for each feature:

(62) Type 2: Morphological case and no obligatory determiners on proper names

$\begin{array}{ccc}{[\text { Kase }} & {[\mathrm{D}} & \left.\left.\left[\mathrm{NP}_{\text {COMMON NOUN }}\right]\right]\right] \\ <\mathrm{e}, \mathrm{e}> & <<\mathrm{e}, \mathrm{t}>, \mathrm{e}> & <\mathrm{e}, \mathrm{t}> \\ {[\text { Kase }} & \left.\left[\mathrm{NP}_{\text {PROPER NAME }}\right]\right] \\ <\mathrm{e}, \mathrm{e}> & \mathrm{e} & \end{array}$

A child learning English or Italian has no evidence for a separate Kase head. There are also no determiners on proper names. ${ }^{32}$ Thus, only one functional layer is projected in the nominal extended projection, as illustrated in (63). (This functional layer then hosts both [+argumental] and [+definite] features.) See Öztürk (2005) for a similar but slightly different proposal for English.

(63) Type 3: No morphological case and no determiners on proper names

$\left[\mathrm{D} \quad\left[\mathrm{NP}_{\text {соммоN Noun }}\right]\right]$

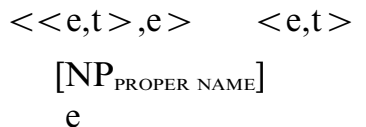

Finally, a child may be facing a language such as Catalan, which lacks morphological case, yet allows determiners on proper names. Given the lack of overt case marking, we may assume that $\mathrm{K}$ is not projected separately. Note, however, that the determiner used with common nouns, $e l$, is a lexical item different from the determiner used with proper names, en. Thus, we may

[32] In standard Italian it has been proposed that determiners are present on proper names under precise pragmatic conditions, namely familiarity (Longobardi 1994). This can be incorporated into our system, by assuming that such determiners do not contribute a uniqueness presupposition and thus do not denote in type $<<\mathrm{e}, \mathrm{t}>, \mathrm{e}>$ but are endowed with a pragmatic feature, such as [+familiarity]. Such dialects would be more like Catalan in terms of our typology. 
assume, without positing unnecessary lexical ambiguity, that the different lexical entries of the definite article have different semantics: the one attaching to common nouns (namely $e l$ ) is a genuine determiner, while the other, attaching to proper names (namely en) is an expletive. Thus, even though one of these determiners, the one that appears on proper names, is semantically expletive, this does not give rise to a split Def-D structure, because the child has no reason to generalize the expletive semantics to a different lexical item. ${ }^{33}$

(64) Type 4: No morphological case and determiners on proper names

$\begin{array}{cc}{\left[\mathrm{D}_{1}\right.} & \left.\left[\mathrm{NP}_{\text {COMMON NOUN }}\right]\right] \\ <<\mathrm{e}, \mathrm{t}>, \mathrm{e}> & <\mathrm{e}, \mathrm{t}> \\ {\left[\mathrm{D}_{2}\right.} & \left.\left[\mathrm{NP}_{\text {PROPER NAME }}\right]\right] \\ <\mathrm{e}, \mathrm{e}> & \mathrm{e}\end{array}$

To sum up, it is only in languages with morphological case AND determiners obligatorily occurring on proper names that a separate Kase head and a split Def-D structure is posited. This structure is necessary for complex DPs, so only such languages may have polydefinites.

\section{Summary}

In this paper we have proposed an analysis of polydefinites in Greek that assimilates them to close appositive DPs: both involve the syntax and semantics of a double-headed structure within which an operation of identification of Referential roles (R-roles) takes place. The only difference between them is that polydefinites also involve noun ellipsis in (at least) one of their subparts. We have explained the characteristic features of the construction: (i) ordering freedom, (ii) restrictive interpretation, and (iii) impossibility of double-headed indefinites. The fact that the uniqueness presupposition associated with definiteness holds of the complex DP has been captured by assuming that the semantic contribution of D is limited. It is a higher head, labelled Def, which contributes the iota operator. D itself is by and large semantically expletive. We have shown that our analysis is superior to alternative analyses in (i) accounting for the set of permissible adjectives, (ii) explaining the presence of multiple determiners, and (iii) accounting for the discourse effects associated with polydefinites. Properties (i) and (iii)

[33] Note that given our assumptions, even if the forms were the same, no split Def-D structure could arise, given that the $[+\arg ]$ feature must be hosted by the highest nominal projection, which must be overt. Due to the lack of morphological case in the language, there would be no appropriate host for the feature in case of a Def-D split. In this hypothetical language, which would lack morphological case and would have identical forms of determiners on proper names and common nouns, we would have to assume lexical ambiguity for these forms. 
follow from the presence of noun ellipsis, while (ii) is the result of R-role identification within the double-headed structure. Finally, we have made a cross-linguistic excursus and identified the necessary parameters (availability of morphological case, obligatoriness of preproprial articles, and possibility of noun ellipsis) that conspire to give rise to this rare construction.

\section{REFERENCES}

Ackema, Peter \& Ad Neeleman. 2004. Beyond morphology: Interface conditions on word formation (Oxford Studies in Theoretical Linguistics). Oxford: Oxford University Press.

Acuña-Fariña, Carlos. 2009. Aspects of the grammar of close apposition and the structure of the noun phrase. English Language and Linguistics I3, 453-48I.

Alexiadou, Artemis. 200I. Adjective syntax and noun raising: Word order asymmetries in the $\mathrm{DP}$ as the result of adjective distribution. Studia Linguistica 55, 2I7-248.

Alexiadou, Artemis. 2006. On the cross-linguistic distribution of (in)definiteness spreading. Presented at the University of Klagenfurt, December 2006. http://ifla.uni-stuttgart. de/institut/mitarbeiter/artemis/handouts/On\%20the \%20crosslinguistic\% $\% 20$ distribution $\% 200$ f. pdf (retrieved io April 2008).

Alexiadou, Artemis, Liliane Haegeman \& Melita Stavrou 2007. Noun phrase in the generative perspective. Berlin: Mouton de Gruyter.

Alexiadou, Artemis \& Chris Wilder. 1998. Adjectival modification and multiple determiners. In Artemis Alexiadou \& Chris Wilder (eds.), Possessors, predicates and movement in the DP, 303-332. Amsterdam: John Benjamins.

Alexopoulou, Dora \& Raffaela Folli. 20I0. Indefinite topics and the syntax of nominals in Italian and Greek. In Mary Byram Washburn, Sarah Ouwayda, Chuoying Ouyang, Bin Yin, Canan Ipek, Lisa Marston \& Aaron Walker (eds.), The 28th West Coast Conference on Formal Linguistics (WCCFL 28) online proceedings, I2 pages. Los Angeles, CA: University of Southern California. https://sites.google.com/site/wccfl28pro/alexopoulou-folli (retrieved 20 October 20II).

Androutsopoulou, Antonia. 1995. The licensing of adjectival modification. In Jose Camacho, Lina Choueiri \& Maki Watanabe (eds.), The I4th West Coast Conference on Formal Linguistics (WCCFL I4), I7-3I. Stanford, CA: CSLI Publications.

Baker, Mark. 2005. Lexical categories. Cambridge: Cambridge University Press.

Baker, Mark \& Osamuyimen T. Stewart. 1999. On double-headedness and the anatomy of the clause. Ms., Rutgers University.

Bittner, Maria \& Ken Hale. 1996. The structural determination of case and agreement. Linguistic Inquiry 27, I-68.

Branco, Antonio \& Francisco Costa. 2006. Noun ellipsis without empty categories. In Stefan Müller (ed.), HPSG 'o6. Stanford, CA: CSLI Publications.

Büring, Daniel. 2003. On D-trees, beans, and B-accents. Linguistics and Philosophy 26, 5II-545.

Campos, Hector \& Melita Stavrou. 2004. Polydefinites in Greek and Aromanian. In Olga Tomic (ed.), Balkan syntax and semantics, I37-173. Amsterdam: John Benjamins.

Chomsky, Noam. 1986. Knowledge of language: Its nature, origin, and use. Westport, CT: Praeger.

Dehé, Nicole \& Yordanka Kavalova. 2007. Parentheticals: An introduction. In Nicole Dehé \& Yordanka Kavalova (eds.), Parentheticals, I-22. Amsterdam: John Benjamins.

Doron, Edit. 1992. Appositive predicates. Belgian Journal of Linguistics 7, 23-33.

Doron, Edit. I994. The discourse function of appositives. Israeli Association of Theoretical Linguistics (IATL) I, 53-65. Beersheba \& Jerusalem: Ben Gurion University of the Negev \& Hebrew University of Jerusalem.

Elbourne, Paul. 2005. Situations and individuals. Cambridge, MA: MIT Press.

Féry, Caroline \& Vieri Samek-Lodovici. 2006. Discussion notes: Focus projection and prosodic prominence in nested foci. Language 82, I3I-I57. 
Giannakidou, Anastasia \& Urtzi Etxeberria. 20I0. Definiteness, contextual domain restriction, and quantifier structure: A crosslinguistic perspective. Ms., The University of Chicago \& IKER Research Centre for the Basque language and Basque texts/ CNRS.

Giannakidou, Anastasia \& Melita Stavrou. 1999. Nominalization and ellipsis in the Greek DP. The Linguistic Review I6, 295-33I.

Giusti, Giuliana. 1995. A unified structural representation of (abstract) case and articles: Evidence from Germanic. In Olsen Haider \& Sten Vikner (eds.), Studies in comparative Germanic syntax, 77-93. Dordrecht: Kluwer.

Haspelmath, Martin, Matthew Dryer, David Gil \& Bernard Comrie (eds.). 2005. The world atlas of language structures. Oxford: Oxford University Press.

Heim, Irene \& Angelika Kratzer. 1998. Semantics in generative grammar. Oxford: Blackwell.

Heycock, Caroline \& Roberto Zamparelli. 2000. Friends and colleagues: Plurality and NPcoordination. In Masako Hirotani, Andries W. Coetzee, Nigel Hall \& Ji-Yung Kim (eds.), The Northeast Linguistics Society (NELS) 30, 34I-352. Amherst, MA: Graduate Linguistic Student Association (GLSA).

Higginbotham, James. 1985. On semantics. Linguistic Inquiry I6, 547-593.

Hiraiwa, Ken \& Adams Bodomo. 2008. Object-sharing as symmetric sharing: Evidence from Dàgáárè. In Charles B. Chang \& Hannah J. Haynie (eds.), The 26th West Coast Conference on Formal Linguistics (WCCFL 26), 243-25I. Sommerville, MA: Cascadilla Press.

Huddleston, Rodney, John Payne \& Peter Peterson. 2002. Coordination and supplementation. In Huddleston \& Pullum et al., I273-I362.

Huddleston, Rodney \& Geoffrey K. Pullum et al. 2002. The Cambridge grammar of the English language. Cambridge: Cambridge University Press.

Ioannidou, Alexia \& Marcel den Dikken. 2009. P-drop, D-drop, D-spread. In Claire Danielle Halpert, Jeremy Hartmann \& David Hill (eds.), The 2007 Worskhop in Greek Syntax and Semantics at MIT (MIT Working Papers in Linguistics 57), 393-408. Cambridge, MA: Department of Linguistics, MIT.

Karanassios, Georgios. 1992. Syntaxe comparé du groupe nominal en grec moderne et dans d'autres langues [Comparative syntax of the nominal phrase in Modern Greek and other languages]. Ph.D. dissertation, Université Paris VIII, Vincennes.

Kariaeva, Natalia. 2004. Determiner spreading in Modern Greek: Split-DP hypothesis. Ms., Rutgers University.

Kolliakou, Dimitra. 2004. Monadic definites and polydefinites: Their form, meanning and use. Journal of Linguistics 40, 263-333.

Krifka, Manfred. 2006. Can focus accenting be eliminated in favor of deaccenting Given constituents? The 9th Symposium on Logic and Language (Besenyötelek, Hungary), I07-II9.

Kripke, Saul. 1980. Naming and necessity. Oxford: Blackwell.

Langacker, Ronald. 1969. On pronominalization and the chain of command. In Daniel Reibel \& Sanford Schane (eds.), Modern studies in English: Readings in transformational grammar, I60-200. Englewood Cliffs, NJ: Prentice Hall.

Lekakou, Marika \& Kriszta Szendröi. 2007. Eliding the noun in close apposition, or Greek polydefinites revisited. UCL Working Papers 19, I29-I54.

Lekakou, Marika \& Kriszta Szendröi. 2009. Close apposition with and without noun ellipsis: An analysis of Greek polydefinites. Studies in Greek Linguistics 29, I5I-I66. Thessaloniki: Institute of Modern Greek Studies.

Lekakou, Marika \& Kriszta Szendröi (in press). The cross-linguistic distribution of polydefinites: Case and expletive determiners. The North East Linguistic Society (NELS) 40.

Leu, Tom. 2007. From Greek to Germanic: Poly $\left({ }^{*}\right.$ in $)$ definiteness and weak/strong adjectival inflection. Ms., New York University.

Löbel, Elisabeth. 1994. KP/DP-syntax: Interaction of case-marking with referential and nominal features. Theoretical Linguistics 20, 38-70.

Longobardi, Giuseppe. 1994. Reference and proper names: A theory of N-movement in syntax and logical form. Linguistic Inquiry 25, 609-665. 
Manolessou, Io. 2000. Greek noun phrase structure: A study in syntactic evolution. Ph.D. dissertation, University of Cambridge.

Marinis, Theodore. 200I. Feature Specification in the Modern Greek DP: Acquiring Reference, Case and Agreement. The 4th International Conference on Greek Linguistics (Nicosia, September 1999), 5I2-519. Thessaloniki: University Studio Press.

Matushansky, Ora. 2009. On the linguistic complexity of proper names. Linguistics and Philosophy 3I, 573-627.

Neeleman, Ad \& Kriszta Szendröi. 2004. Superman sentences. Linguistic Inquiry 35, I49-I59.

Neeleman, Ad \& Hans van der Koot. 2002. The configurational matrix. Linguistic Inquiry 33, 529-574.

Neeleman, Ad \& Fred Weerman. 1998. Flexible syntax: A theory of case and arguments. Dordrecht: Kluwer.

Ntelitheos, Dimitrios. 2004. Syntax of elliptical and discontinuous nominals. MA thesis, UCLA.

Öztürk, Balkiz. 2005. Case, referentiality and phrase structure. Amsterdam \& New York: John Benjamins.

Panagiotidis, Phoevos. 2003. Empty nouns. Natural Language \& Linguistic Theory 2I, $38 \mathrm{I}-432$.

Panagiotidis, Phoevos \& Thodoris Marinis. 20II. Determiner spreading as DP-predication. To appear in Studia Linguistica.

Partee, Barbara H. 1986. Noun phrase interpretation and type-shifting principles. In Jeroen Groenendijk, Dick de Jongh \& Martin Stockhof (eds.), Studies in Discourse Representation Theory and the Theory of Generalized Quantifiers, II 5-I43. Dordrecht: Foris.

Payne, John \& Rodney Huddleston. 2002. Nouns and noun phrases. In Huddleston \& Pullum et al., 323-523.

Pesetsky, David \& Esther Torrego. 200I. T-to-C movement: Causes and consequences. In Michael Kenstowicz (ed.), Ken Hale: A life in language, 355-426. Cambridge, MA: MIT Press.

Potts, Christopher. 2005. The logic of conventional implicature. Oxford: Oxford University Press.

Ralli, Angela. 1992. Compounds in Modern Greek. Rivista di Linguistica 4, I43-I74.

Ralli, Angela \& Melita Stavrou. 1998. Morphology-syntax interface: A-N compounds vs. A-N constructs in Modern Greek. In Geert Booij \& Jaap van Marle (eds.), Yearbook of morphology 1997, 243-264. Dordrecht: Springer.

Reinhart, Tanya. 2006. Interface strategies. Cambridge, MA: MIT Press.

Roberts, Craige. 1996. Information structure in discourse: Towards an integrated formal theory of pragmatics. In Jae-HakYoon \& Andreas Kathol (eds.), Papers in semantics (OSU Working Papers in Linguistics 49), 9I-I36. Columbus, OH: Department of Linguistics, The Ohio State University.

Schwarzchild, Roger. 1999. GIVENness, Avoid F, and other constraints on the placement of accent. Natural Language Semantics 7, I4I-I77.

Stavrou, Melita. 1995. Epexegesis vs. apposition. Scientific yearbook of the Classics Department, 217-250. Thessaloniki: Aristotle University of Thessaloniki.

Stavrou, Melita. 1996. Adjectives in Modern Greek: An instance of predication, or an old issue revisited. Journal of Linguistics 32, 79-II2.

Stavrou, Melita. 2009. Postnominal adjectives in Greek indefinite noun phrases. Ms., Aristotle University of Thessaloniki. [To appear In Laura Brugè, Anna Cardinaletti, Giuliana Giusti, Nicola Munaro \& Cecilia Poletto (eds.), Functional heads: Papers in honour of Guglielmo Cinque for his 6oth anniversary, Oxford University Press.]

Szabolcsi, Anna. 1994. The noun phrase. In Ferenc Kiefer \& Katalin. E. Kiss (eds.), The syntactic structure of Hungarian (Syntax \& Semantics 27), 179-275. New York: Academic Press.

Szendröi, Kriszta. 20I0. A flexible approach to discourse-related word order variations in the DP. Lingua I20, 864-878.

Tsimpli, Ianthi Maria \& Stavroula Stavrakaki. 1999. The effects of a morphosyntactic deficit in the determiner system: The case of a Greek SLI child. Lingua I08, 3I-85.

Velegrakis, Nikolaos. 20II. The syntax of Greek polydefinites. Ph.D. thesis, University College London.

Williams, Edwin. 198I. Argument structure and morphology. The Linguistic Review I, 8I-II4. 


\section{POLYDEFINITES IN GREEK}

Williams, Edwin. 1989. The anaphoric nature of theta-roles. Linguistic Inquiry 20, 425-256.

Williams, Edwin. 1994. Thematic structure in syntax. Cambridge, MA: MIT Press.

Williams, Edwin. 1997. Blocking and anaphora. Linguistic Inquiry 28, 577-628.

Zeijlstra, Hedde. 2004. Sentential negation and negative concord. Ph.D. dissertation, University of Amsterdam.

Zwarts, Joost. I993. X-bar syntax, X-bar semantics. Ph.D. dissertation, University of Utrecht.

Authors' addresses: (Lekakou)

Goethe Universität Frankfurt am Main, Institüt für Linguistik,

Grüneburgplatz I, D-60629 Frankfurt am Main, Germany

lekakou@em.uni-frankfurt.de

(Szendröi)

Division of Psychology and Language Sciences, Faculty of Life

Sciences, University College London, Chandler House,

2 Wakefield Street, London WCIN IPF, UK

k.szendroi@ucl.ac.uk 